Originally published as:

Mühle, M., Hoffmann, K., Löchelt, M., Denner, J.

Immunisation with foamy virus Bet fusion proteins as novel strategy for HIV-1 epitope delivery (2013) Immunologic Research, 56 (1), pp. 61-72.

DOI: $10.1007 / \mathrm{s} 12026-013-8387-x$

This is an author manuscript.

The definitive version is available at: http://link.springer.com/ 


\title{
Immunisation with foamy virus Bet fusion proteins as novel strategy for HIV-1 epitope delivery
}

\author{
Michael Mühle ${ }^{1}$, Kerstin Hoffmann ${ }^{1}$, Martin Löchelt ${ }^{2}$, Joachim Denner ${ }^{1}$ *
}

\footnotetext{
${ }^{1}$ Robert Koch Institute, Center for HIV and Retrovirology, Berlin, Nordufer 20, 13553 Germany

${ }^{2}$ German Cancer Research Center (DKFZ), Research Topic Infection and Cancer, Division Genome Modifications and Carcinogenesis, Heidelberg, Im Neuenheimer Feld 242, 69120 Germany
}

\footnotetext{
* Corresponding author.

Robert Koch Institute, Berlin, Nordufer 20, 13553 Germany

Phone: +4930187542800

E-mail address: DennerJ@rki.de
} 


\begin{abstract}
The induction of 2F5- and 4E10-like antibodies broadly neutralising HIV-1 and targeting the membrane external proximal region (MPER) of the transmembrane envelope protein gp41 would be a major advancement for the development of a preventive HIV-1 vaccine but successful attempts remain rare. Recent studies demonstrated that broadly reactive antibodies develop relatively late during infection and after intensive affinity maturation. Therefore, a prolonged antigen delivery might be beneficial to induce them. Replicating foamy viruses which are characterised by apathogenic but persistent infection could represent suitable carrier viruses for this purpose. In order to develop such a system, we modified the accessory foamy virus Bet protein to contain the MPER of gp41, or the MPER linked to the stabilising fusion peptide proximal region (FPPR) of gp41 and analysed here the antigenic and immunogenic properties of such hybrid proteins. The antigens, expressed and purified to homogeneity, were recognised by the monoclonal antibodies 2F5 and 4E10 with nanomolar affinities and induced high levels of antibodies specific for gp41 after immunisation of rats. The antisera also bound to virus particles attached to infected cells and peptide-based epitope mapping showed that they recognised the 2F5 epitope. Although no HIV-1 neutralising activity was observed, the presented data demonstrate that using the foamy virus Bet for HIV-1 epitope delivery is successfully applicable. Together with the attractive potential for sustained antigen expression after transfer to replicating virus, these results should therefore provide a first basis for the development of chimeric foamy viruses as novel HIV-1 vaccine vectors.
\end{abstract}

Keywords

HIV-1; vaccine; MPER; foamy virus; Bet protein

\title{
INTRODUCTION
}

For HIV-1 vaccine development, induction of broadly neutralising antibodies (bnAb) is the most promising approach to prevent infection and to avoid integration of the provirus into the genome of the target cell where it may persist $[1,2]$. The viral envelope proteins composed of the surface and transmembrane (TM) subunits are the main target of neutralising antibodies and several potent bnAb directed against each subunit have been isolated from infected patients (reviewed in $[3,2]$ ). Most of these antibodies show unique properties such as a high degree of somatic mutation, prolonged CDR3 loops and polyreactivity and occur in about $20 \%$ of infected individuals only after about 4 years of infection [47]. The findings suggest that these antibodies may arise from rare B-cell stimulation events or after intensive affinity maturation $[8,1,6]$, which is only partly achieved by repeated antigen administration [9]. Given that various attempts to induce bnAb completely failed or resulted in low-titred neutralising antibody responses with limited breadth [2] alternative approaches should be explored. Replicating viral vectors and attenuated vaccines have been found to be the most effective way to prevent infection in the non-human primate model [1013] and permit long-term antigen delivery by simultaneously stimulating strong cellular immune responses [10]. However, most of the replicating systems available to date raise safety concerns that limit/exclude their application in 
humans [14]. Foamy viruses (FV) are apathogenic viruses of the Spumaviriniae subfamily which are characterised through persistent infection, preferential integration sites, genetic stability and wide tissue tropism [15-18], favouring their application for gene therapy and vaccine purposes [19-22]. Similarly, the feline foamy virus (FFV) was used as convenient model for the application in cats [2326]. In order to develop a vector system that could be tested in small animals and encouraged by previous immunisation studies with an antigen of the feline calicivirus [25], a strategy for HIV-1 epitope delivery using the accessory FFV Bet protein was evaluated here. Bet is particularly useful as carrier antigen as it is highly expressed in infected cells resulting in a strong antibody response in infected animals [27-29] and it was reported to be secreted and taken up by adjacent cells [30,31], permitting the presentation of proteasome-unprocessed conformational epitopes to immune cells. As HIV-1 antigen, the membrane proximal external region (MPER) of the TM protein gp41 of HIV was selected to be appended to the FFV Bet protein. This domain is targeted by three bnAb, 2F5, $\mathrm{Z13}$ and 4E10, and is therefore of particular interest as vaccine target [32-35]. However, MPER-based vaccine development is complicated by the structural flexibility of the MPER required to promote membrane fusion and uncertainty about the conformation able to induce bnAb [36-41]. Furthermore, the necessity for a lipid environment for induction of MPER directed bnAb is still under intensive investigation [42, 43]. In structural analyses, the 2F5-bound epitope ELDKWA forms a slightly distorted type $1 \beta$-turn compared with an $\alpha$-helical structure when the MPER is analysed alone [37, 44, 39]. Importantly, 2F5 also shows a higher affinity to antigens fixing its epitope as a $\beta$-turn compared to an $\alpha$ helix, indicating that this conformation might resemble the initial B-cell trigger [45-48]. In contrast, the bnAb 4E10 recognises the adjacent $\alpha$-helical core sequence NWFN/DIT in the MPER and its affinity is enhanced when the antigens support $\alpha$-helical structures [49-51]. Recent investigations supported an interaction of the MPER with the fusion peptide proximal region (FPPR) of gp41 and also showed that peptides corresponding to the FPPR increased binding of 2 F5 to its epitope [52-55]. This was attributed to a FPPR-induced orientation of MPER residues coinciding with an increased level of $\beta$-turn/ $\beta$-sheet conformation $[56,57]$. In order to use its constraining property, an additional antigen containing the FPPR and the MPER was included here. With the objective to evaluate bnAb binding to such novel Bet/HIV-1 gp41 hybrids before transfer to replicating FFV and to study the epitope specificity of antibodies obtained in response to vaccination, recombinant fusion proteins of the FFV Bet protein and the MPER and FPPR sequences of gp41 of HIV-1 were produced in this study, characterised and the antibody response in immunised rats was studied.

\section{MATERIAL AND METHODS}

\section{Expression plasmids}

To clone pQE-Bet and pQE-Bet/HIV-1 constructs, the complete FFV Bet sequence (Uniprot ID O93036) with additional four amino acids (AGAA) was amplified from the plasmid pBC12-Bet with the primers FFV Bet-fwd (5'atggcttcaaaatacccggaagaaggacca-3') and FFV Bet-rev (5'-tcatctgactctgaagctggt- 
gcagccggctag-3') containing a NaeI site and introduced into the StuI and BamHI linearised prokaryotic expression vector pQE-30-Xa (Qiagen, Hilden, Germany). The constructs pQE-BetE1, pQE-BetE2 and pQE-BetE1-E2 were obtained by subcloning E1, E2 or E1-E2 sequences (Fig. 1A) with additional N-terminal linker amino acids (SGSAGAGAGGG) from two synthetic plasmids (GeneArt, Regensburg, Germany) which were introduced into the NaeI/HindIII digested pQE-Bet vector. All constructs were verified by sequencing.

\section{Protein purification}

After optimisation in 96 deep well plates [58], proteins were expressed in Escherichia coli SCS-1 bacteria (Agilent Technologies, Austin, USA) using 2YT medium, $37^{\circ} \mathrm{C}$ and $1 \mathrm{mM}$ IPTG. For lysis, bacterial pellets were resuspended in PBS containing $0.1 \mathrm{mg} / \mathrm{ml}$ lysozyme, incubated on ice for $15 \mathrm{~min}$ and then sonicated for $3 \times 20 \mathrm{~s}$. Inclusion bodies were collected by centrifugation (10.000 $\mathrm{g}, 20 \mathrm{~min})$ and resuspended in buffer $\mathrm{A}\left(100 \mathrm{mM} \mathrm{NaH}_{2} \mathrm{PO}_{4}, 10 \mathrm{mM}\right.$ TrisHCl, $6 \mathrm{M}$ $\mathrm{GuHCl}, 300 \mathrm{mM} \mathrm{NaCl}, 10 \mathrm{mM}$ imidazole, $\mathrm{pH} \mathrm{8.0).} \mathrm{After} \mathrm{centrifugation} 2 \mathrm{~h}$ later $\left(25.000 \mathrm{~g}, 20 \mathrm{~min}, 4^{\circ} \mathrm{C}\right)$, the supernatant was loaded onto a HisTrap Ni-NTA column (GE Healthcare, Munich, Germany), washed with buffer B (100 mM $\mathrm{NaH}_{2} \mathrm{PO}_{4}, 10 \mathrm{mM}$ TrisHCl, $8 \mathrm{M}$ urea, $300 \mathrm{mM} \mathrm{NaCl}, 10 \mathrm{mM}$ imidazole, $\mathrm{pH} 8.0$ ) and bound proteins released using buffer $\mathrm{C}\left(100 \mathrm{mM} \mathrm{NaH}_{2} \mathrm{PO}_{4}, 10 \mathrm{mM}\right.$ TrisHCl, $8 \mathrm{M}$ urea, $300 \mathrm{mM} \mathrm{NaCl}, 500 \mathrm{mM}$ imidazole, $\mathrm{pH} 8.0)$. Eluted fractions (2 mg/ml) were incubated with $20 \mathrm{mM} \beta$-mercaptoethanol for at least $3 \mathrm{~h}$ and renatured by 1:20 dilution in refolding buffer $(50 \mathrm{mM}$ HEPES, $300 \mathrm{mM} \mathrm{NaCl}, 100 \mathrm{mM} \mathrm{L}$ arginine, $\mathrm{pH}$ 9.0) for $24 \mathrm{~h}$ at room temperature followed by dialysis overnight against phosphate buffer $\left(50 \mathrm{mM} \mathrm{NaH}{ }_{2} \mathrm{PO}_{4}, 300 \mathrm{mM} \mathrm{NaCl}, \mathrm{pH}\right.$ 8.0). Proteins were concentrated by another Ni-NTA chromatography step using imidazolesupplied phosphate buffers.

\section{ELISA and serum titration}

ELISA plates (Greiner Bio-One, Frickenhausen, Germany) were coated with 100 ng/well of Bet/HIV-1 antigens, or $200 \mathrm{ng} /$ well of purified gp41 (Uniprot ID P04578, amino acids 532-681) expressed in bacteria or synthetic HIV peptides (E1: AAGSTMGAASMTLTVQARLLLS-KKKK, E2: KKKKEQELLELDKWASLWNWFNITNWL, GeneCust, Dudelange, Luxembourg) and then blocked for 1 $h$ at $37^{\circ} \mathrm{C}$ with $5 \%$ BSA in PBS $/ 0.05 \%$ Tween (PBS-T). For each serum a tenfold dilution in $2.5 \%$ BSA with PBS-T was prepared in triplicates and plates were then incubated with the samples for $1 \mathrm{~h}$ at $37^{\circ} \mathrm{C}$. After washing and addition of a peroxidase (HRP) coupled anti-rat IgG-HRP antibody (Dako, Hamburg, Germany, 1:3000) plates were developed with OPD (o-phenylendiamine dichloride) and read at $492 \mathrm{~nm}$. For calculation of endpoint titres, the absorbance measured for immune sera at every dilution was plotted against the dilution step and data were fitted by a logarithmic regression function. Endpoint titres were defined as the highest serum dilution exceeding the mean absorbance of six control wells of pre-immune serum plus three standard deviations, corresponding to a confidence level of $98 \%$ [59]. Data were statistically evaluated using the VassarStats software (http://vassarstats.net) by applying Shapiro-Wilk and F-test 
analysis for testing normal distribution and equality of variances. For comparisons between groups the Kruskal-Wallis one-way analysis of variance and the Welch-ttest for direct comparison between two groups was used. Differences were considered significant, if $\mathrm{p}$-values below 0.05 were obtained.

\section{Surface plasmon resonance (SPR)}

SPR measurements were performed on a Biacore X100 device with anti-human IgG-Fc specific antibodies immobilised on CM5 chips (all GE Healthcare, Munich, Germany). 2F5 or $4 \mathrm{E} 10$ in $50 \mathrm{mM} \mathrm{NaH}_{2} \mathrm{PO}_{4}, 300 \mathrm{mM} \mathrm{NaCl}, \mathrm{pH} 8.0$ were captured at 300-500 response units (RU) on flow cell 2 and three increasing concentrations of fusion proteins diluted in $50 \mathrm{mM} \mathrm{NaH}_{2} \mathrm{PO}_{4}, 300 \mathrm{mM} \mathrm{NaCl}, \mathrm{pH}$ 8.0 were injected on both flow cells. After regeneration with $10 \mathrm{mM}$ glycine, $\mathrm{pH}$ 2.0, and antibody recapturing, blank resonance was measured by three injections of dilution buffer. Sensograms were reference cell subtracted and blank normalised values from at least two repeated experiments. Curves were fitted using the 1:1 Langmuir algorithm and quality of fitting was checked by assuring $\mathrm{K}_{\mathrm{D}}$ values in the range of measured protein concentrations, plausible $\mathrm{R}_{\max }$ values, small $\chi^{2}$ values as well as residuals within recommended borders.

\section{Immunisation}

Wistar rats (Charles River, Wilmington, USA) in groups of four were immunised three times at intervals of three weeks with $250 \mu \mathrm{g}$ of each antigen. $1 \mathrm{ml}$ of protein emulsified in Freund's adjuvant were injected either subcutaneously (s.c) at four sites of the animal for the first injection or s.c. $(4 \mathrm{x} 200 \mu \mathrm{l})$ and intramuscularly $(2 \mathrm{x}$ $100 \mu \mathrm{l})$ for the second and third injection. Blood was taken by retrobulbar bleeding before immunisation (pre-immune sera, PI), two days before boost injections and three weeks after the last boost (serum 1, 2 and 3, respectively). All manipulations were in accordance with regular animal welfare guidelines and approved by the Landesamt für Gesundheit und Soziales, Berlin, Germany.

\section{Epitope mapping}

Epitope mapping was performed with PepStar peptide microarrays (JPT, Berlin, Germany) spotted with 15 mer peptides (12 residues overlap) of the extended HIV-1 HXB2 FPPR domain (amino acids 512-559) and the extended MPER domain (amino acids 644-691) as well as rat IgG as internal control. Sera were incubated on the array using a 24 multi-well hybridisation chamber (ArrayIt, Sunnyvale, USA) following the protocol recommended by JPT. Bound antibodies were detected using a DyLight 649 conjugated AffiniPure goat anti-rat IgG antibody (Jackson Immuno Research Labs, West Grove, USA, 1:500) and read at $635 \mathrm{~nm}$ in a GenePix 4000 microarray scanner (Molecular Devices, Sunnyvale, USA). Epitopes were defined as central amino acids shared by overlapping peptides with signal intensities above a 5000 RLU threshold. 


\section{Flow cytometry and immunofluorescence}

C8166 cells were infected at a MOI of 0.5 with cell free supernatants obtained from pNL-4.3 transfected $293 \mathrm{~T}$ cells and further cultivated for $48 \mathrm{~h}$ or $72 \mathrm{~h}$ for indirect immunofluorescence or FACS analysis, respectively. Non-infected C8166 cells were assayed in parallel to assure the specificity of staining and no binding was observed (not shown). Cells were pelleted and washed twice with PBS, fixed by incubation with $2 \%$ paraformaldehyde in PBS for $15 \mathrm{~min}$ and then used either directly for FACS staining or attached to poly-lysine coated glass slides, dried and rehydrated in PBS overnight. Samples were blocked with 10\% normal goat serum in PBS for $1 \mathrm{~h}$ and then antisera or a pre-immune rat serum as control (all 1:100 in $3 \%$ goat serum, PBS) applied for $1 \mathrm{~h}$. Cells were washed with PBS followed by incubation with a goat anti-rat IgG-FITC conjugated secondary antibody (SantaCruz Biotechnology, Santa Cruz, USA, 1:400), washed again and then either analysed in a FACS Calibur flow cytometer (Becton-Dickinson, Heidelberg, Germany) or embedded in DAPI containing mounting medium (Vectashield, Vector Laboratories, Burlingame, USA) for analysis on a Zeiss Axiovert 200 microscope using Cell-F imaging software (Olympus, Hamburg, Germany).

\section{Neutralisation assay}

TZM-bl cells $\left(1 \times 10^{4} /\right.$ well) were seeded in a 96 well cell culture plate. The next day, antisera were diluted 1:25 with medium and $50 \mu \mathrm{l}$ of the dilution were incubated with $50 \mu \mathrm{l}$ of 200 infectious units of titrated HIV-1 pNL4.3 for $30 \mathrm{~min}$ at $37^{\circ} \mathrm{C}$ and then added to the cells. As controls, non-infected, infected, and cells incubated with virus and 2F5 were used. Infection was analysed after $48 \mathrm{~h}$ by staining the cells with X-Gal solution $\left(5 \mathrm{mM} \mathrm{K}_{3} \mathrm{Fe}(\mathrm{CN})_{6}, 5 \mathrm{mM} \mathrm{K}_{4} \mathrm{Fe}(\mathrm{CN})_{6}, 2\right.$ $\mathrm{mM} \mathrm{MgCl} 2,1 \mathrm{mg} / \mathrm{ml} \mathrm{X-Gal} \mathrm{in} \mathrm{PBS)} \mathrm{and} \mathrm{ELISPOT} \mathrm{counting} \mathrm{as} \mathrm{described}$ previously [60]. Neutralisation was defined as $50 \%$ reduction of stained cells when immune sera and pre-immune sera were compared. 


\section{RESULTS}

\section{Antigen design, production and purification}

To add HIV-1 gp41 sequences to the bet sequence of FFV, a Bet expression vector was constructed in which the FPPR-derived E1 sequence, the MPERderived E2 sequence or both E1 and E2 sequences connected by a loop sequence were subsequently introduced to the C-terminus (Fig. 1a, b). Between Bet and the corresponding HIV-1 parts, a flexible 15 amino acid glycine-serine-rich linker was introduced with the intention that HIV-1 epitopes protrude from the fusion partner and are thus more accessible for antibodies and immune cells. The E1-E2 loop construct used here was derived from the previously described alpha-turnalpha peptide [61], which promotes the interaction of the alpha helical parts as a coiled coil [62]. Replacing the original alpha helices by HIV-1 FPPR and MPER domains except for eight amino acids flanking both termini of the loop, the construct was designed to mimic a form of gp41, where MPER and FPPR are in close proximity [63]. Additionally, both domains were connected with an amino acid spacing that allows interaction of contacting residues as found in the crystal structure of gp41 [38]. This construct was optimised and validated by secondary structure prediction algorithms and $\alpha$-helical wheel projections to fit the desired criteria (Online Resource 1). Then, all three fusion proteins and Bet alone were produced in E. coli, purified by affinity chromatography and refolded by rapid dilution with typical yields of 11-18 mg/L expression culture. Characterisation of the antigens by SDS-PAGE showed their purity which usually exceeded $90 \%$ as judged by densitometric scanning of Coomassie stained gels (Fig. 1c).

\section{Recognition of the produced antigens by 2F5 and 4E10}

To examine their reactivity with $2 \mathrm{~F} 5$ and $4 \mathrm{E} 10$, antigens were first analysed in a Western blot assay. 2F5 and to a weaker extent also 4E10 reacted with all antigens containing the MPER epitopes but not with the unmodified Bet or the Bet-E1 protein (Fig. 1d). Conversely, an epitope-mapped rat antiserum specific for the HIV-1 gp41 FPPR (recognising the epitope 541-TLTVQARQL-570) reacted with all E1-containing proteins but not with the Bet-E2 antigen (Fig. 1d). Since denatured gp41 was generally better recognised by 2 F5 and worse by 4E10 when compared to soluble gp41 [64], binding to non-denatured proteins was investigated in parallel (Fig. 2). In the case of 2F5 minor differences in binding to the different E2-hybrid antigens were observed, with a reduced binding to the BetE1-E2 protein (Fig. 2). In contrast, 4E10 bound strongly to the Bet-E1-E2 loop antigen, but poorly to the Bet-E2 or the combination of the Bet-E1 and Bet-E2 proteins and as expected not to Bet-E1 (Fig. 2). These results demonstrated that all hybrid antigens properly displayed the corresponding HIV-1 domain(s) and that the presence of the E1 domain was beneficial for the presentation of the 4E10 but not the 2F5 epitope. 


\section{SPR analysis of 2F5 and 4E10 binding to the produced antigens}

To study the binding of 2F5 and 4E10 to the hybrid proteins in more detail, SPR experiments were performed (Table 1, Online Resource 2). 2F5 binding to antigens containing the MPER alone or in combination with the FPPR domain was detectable down to the nanomolar range $\left(\mathrm{K}_{\mathrm{D}}=4.8,5.9\right.$ and $19 \mathrm{nM}$ for Bet-E2, Bet-E1+Bet-E2 and Bet-E1-E2, respectively) whereas no interaction was observed for the Bet-E1 control construct (Table 1, Online Resource 2). As above, no increase in binding was measured when a mixture of Bet-E2 and Bet-E1 was tested. Also, the affinity of 2F5 to the loop antigen was lower compared to Bet-E2 due to a twofold slower association and dissociation rate (Table 1). In line with the weaker Western blot and ELISA reactivity of 4E10, much higher fusion protein concentrations were needed in the SPR studies. Due to the precipitation of recombinant Bet/HIV-1 proteins above $1 \mathrm{mg} / \mathrm{ml}$ (corresponding to $15-20 \mu \mathrm{M}$ ) no suitable concentration ranges to obtain reliable data for the Bet-E2 antigen and the combination of Bet-E2 and Bet-E1 could be selected. At the highest concentration tested $(8 \mu \mathrm{M})$, no binding of Bet-E1 and a weak signal (15 RU) for Bet-E2 was observed suggesting that the $\mathrm{K}_{\mathrm{D}}$ values of Bet-E2 were probably in the micromolar range (data not shown). However, when Bet-E1-E2 was analysed, kinetic constants could be determined, since nanomolar protein concentrations yielded stable data (Table 1). The dissociation constant of $223 \mathrm{nM}$ resulted from slow target recognition $\left(\mathrm{k}_{\mathrm{on}}=2.08 \times 10^{3} \mathrm{M}^{-1} \mathrm{~s}^{-1}\right)$ and a moderate dissociation rate $\left(\mathrm{k}_{\text {off }}=4.66 \times 10^{-4}\right.$, Table 1$)$. Thus, the SPR data substantiated the ELISA results and the beneficial effect of the FPPR residues for enhanced 4E10 antibody binding.

\section{Immunogenicity of fusion proteins}

After validation of their antigenicity, rats were immunised with the fusion proteins. All animals showed a strong immune response to the administered antigens with antibody titres of $10^{4}-10^{6}$ already after the first immunisation (Fig. 3, Online Resource 3). The response peaked after the second injection and then remained at this level or slightly decreased, with no significant differences between the groups (Kruskal-Wallis, $p=0.262, p=0.243$ and $p=0.385$ for first, second, and third immunisation, respectively). To study the immune response against the introduced HIV-derived E1 and E2 domains and to analyse whether these antibodies are also able to bind to gp41 of HIV-1, ELISA were performed using synthetic E1 and E2 peptides as well as purified recombinant gp41 produced in bacteria. All sera recognised the HIV-1 peptides as well as gp41 with titres ranging from $10^{2}$ up to $10^{5}$ (Fig. 4, Online Resource 4). Notably, the reaction against the E1 domain (mean titre $10^{5}$ ) was significantly stronger than that against the E2 domain (mean titer $10^{3}$ ) in groups immunised with Bet-E1 and Bet-E2 antigen (Welch-t-test $p=0.027$, Fig. $4 a$ and $b$ ). This was also true for sera from animals immunised with a mixture of both hybrid antigens $(p=0.0238)$ but did not reach significance in case of the hybrid E1-E2 loop antigen $(p=0.1565$, Fig. $4 \mathrm{c}$ and d). Among all, animals immunised with the Bet-E2 protein alone developed the strongest antibody response against the E2 peptide with mean titres up to $8 \times 10^{3}(\mathrm{p}=0.1274$ and 0.0729 for comparisons to groups 366 and 375 , respectively), followed by animals immunised with the mixture of Bet-E1 plus Bet-E2 ( $p=0.0809$ for group 375, Fig. 4b and b, Online Resource 4). The antibody response against recombinant gp41 correlated well with that against each 
individual domain (Fig. 4a-d) and was confirmed by Western blot analysis (Online Resource 5). Taken together, these results demonstrated that all antigens used were highly immunogenic and that HIV-1 specific antibodies were induced.

\section{Epitope mapping of the antisera}

By mapping sera using overlapping peptides corresponding to the FPPR and MPER, distinct epitopes were identified (Fig. 5). As shown by two representative mappings, all rats immunised with the Bet-E1 hybrid antigen developed a strong response against the E1 domain with the epitope TLTVQARQL. Administration of the Bet-E2 hybrid antigen to rats resulted in antibodies recognising the epitopes ELLELDKWA or ELLELDKWASLW overlapping with the 2F5 epitope (underlined). Sera from animals immunised with a mixture of the E1 and E2 hybrid protein showed a predominant response to the E1 epitope TLTVQARQL and a rather weak response to the E2 epitope NEQELLELDKWASLW. When sera from animals treated with the Bet-E1-E2 loop antigen were investigated, the main response was directed against the E1 epitope TLTVQARQL, but the E2 response was variable, with one serum reacting with NEQELLELDKWA whereas no MPER reactivity was observed in case of a second animal (Fig. 5). These results were consistent with the prior ELISA titration experiments and confirmed the overall lower E2 reactivity observed before. In terms of consistency and strength in which 2F5 epitope-specific antibodies were induced, the Bet-E2 antigen appeared to be superior to all other antigens.

\section{Binding of induced antibodies to infected cells}

Since prior analysis of antibody binding was mainly based on shorter fragments of the full length Env, the binding of antisera to native protein as presented on the surface of infected cells should be also investigated. Therefore, C8166 cells were infected with HIV-1 and binding of antisera from animals with strong antibody titres along with a pre-immune rat serum as control were analysed by flow cytometry and indirect immunofluorescence (Fig. 6). Neglectable binding was observed with the control serum, but sera from immunised animals showed profound fluorescence ranging from moderate to strong dependent on the immunised antigen (Fig. 6a). Recognition of infected cells by the serum from group 364 (Bet E1) was rather weak (28.7\%), however, rat sera from groups 365, 366 and 375 reacted intensely with $65.9,55.5$ and $57.9 \%$, respectively. In indirect immunofluorescence analysis, the same sera gave signals with varying appearance. Antisera of rats 364, containing only FPPR directed antibodies (Fig. 4, Fig. 5) caused rather weak and diffuse staining with no clear pattern. In contrast, all antisera that contained E2 directed antibodies (rats 365, 366, 375) gave spot-like signals distributed on the surface of the cells, most probably showing antibodies binding to the produced or infecting virus (Fig. 6b). This observation was in line with the finding that the gp41 MPER is most accessible in a fusion intermediate state after attachment of gp120 to its cellular receptors [65, 66]. Thus, at least antisera with MPER specificity seemed to be able to react with native Env as mandatory for virus neutralisation. 


\section{Analysis of neutralising activity}

Although some of the immunised animals developed antibodies binding to epitopes overlapping with the $2 \mathrm{~F} 5$ epitope and bound to virus particles, all sera did not prevent HIV-1 infection in a TZM-bl indicator cell line-based neutralisation assay when used at dilutions of 1:50 (Online Resource 6). 2F5 was effectively inhibiting infection.

\section{DISCUSSION}

In the present study a novel strategy for HIV-1 epitope delivery based on FFVBet/HIV-gp41 fusion proteins containing the epitopes of the bnAb 2F5 and 4E10 was evaluated. Milligram amounts of these proteins as needed for immunisation and antigen characterisation were produced in E. coli, purified to homogeneity and renatured to obtain soluble molecules. The antigens specifically reacted with 2F5, 4E10 and a serum against the E1 domain and were immunogenic in rats generating antibodies targeting an epitope overlapping with the 2F5 epitope; however, they did not prevent HIV-1 infection in a TZM-bl based neutralisation assay. The antigens comprised the HIV-1 MPER-derived E2 domain because the corresponding bnAb antibodies are characterised by strong somatic mutations which could benefit from prolonged antigen delivery by replicating vectors [67]. Additionally, some Bet hybrids contained the FPPR derived E1 domain and the E2 domain linked by a loop to stabilise a MPER conformation that increases 2F5 binding [56, 53, 57, 54]. Introducing the MPER domain alone resulted in high affinity recognition by $2 \mathrm{~F} 5$, with values comparable to or better than previously reported for MPER peptides or MPER epitope scaffolds [68, 47, 69]. Unexpectedly, the affinity of $2 \mathrm{~F} 5$ to its epitope decreased to some extent when the FPPR residues were present (Table 1). This suggests that the selected positioning of the FPPR residues might not allow proper orientation of the 2F5 epitope or formation of the affinity enhancing $\beta$-turn structure and might result from a divergence between the bioinformatic predictions used to design this antigen and the actual structure. However, by stepwise optimisation of the FPPR and MPER epitope presentation with an extended set of loop antigens, enhanced antigenicity of 2F5 was observed in later experiments (Mühle et al, in preparation). In contrast to 2 F5, the FPPR residues remarkably improved 4E10 binding (Fig. 2, Table 1). Crystallisation experiments with 2F5-Fab have shown that the presence of FPPR residues not only stabilised the $\beta$-turn structure of the $2 \mathrm{~F} 5$ epitope but also induced the formation of $\alpha$-helices in the adjacent $C$-terminal residues [56]. Such an increase in $\alpha$-helical content might explain the higher affinity of $4 \mathrm{E} 10$ to the loop construct used here, since enhanced binding for 4E10 to $\alpha$-helical peptides has been reported [50]. However, the affinity of 4E10 to the loop antigen was still weak when compared to $2 \mathrm{~F} 5$ (223 nM compared to $19 \mathrm{nM}$, Table 1) or previous antigens designed for induction of 4E10-like antibodies [49, 50] and potentially explains the 2F5 epitope-dominated response observed (Fig. 5). For improvement, the E2 domain may be extended by at least three additional amino acids (YIK) to increase the affinity for 4E10 [49, 50].

When used as protein immunogen, Bet was found to be an effective carrier molecule for the small HIV-1 epitopes, triggering a profound humoral response to the introduced inserts (Fig. 4, Online Resource 4). Importantly, antibodies 
targeting ELDKWA and binding to gp41 and virions were induced, particularly with the Bet-E2 antigen which also showed the highest affinity to $2 \mathrm{~F} 5$ and the strongest antibody response against the MPER (Table 1, Fig. 4). Despite the high titres of binding antibodies, none of the immune sera were neutralising, indicating that high affinity and immunogenicity do not predict the ability of antigens to induce antibodies capable to prevent HIV-1 infection as was found also by others $[68,47,70,48]$. It is difficult to judge whether the antigens used here did not provide a conformation able to induce neutralising antibodies or whether their amount in the antibody population was too low to be detected. To further increase MPER-specific responses, certain mutations that have been recently described to enhance its immunogenicity could be beneficial [71]. Also, in order to avoid the FPPR-dominated responses observed here when the E1 domain was present, introduction of a glycosylation site into the FPPR might be considered to immunologically silence the E1 reactivity and focus the immune system to the MPER region [72]. As the antisera were binding to virus particles (Fig. 6) but were not neutralising, one could speculate that the induced antibodies lack certain characteristics like (i) lipid binding, which is not promoted by the strategy used here, or (ii) prolonged CDRH3 loops, which could arise as a result of somatic mutation after extended B-cell stimulation. Whereas the first point will have to be tested with other strategies, e.g. by placing the HIV-1 MPER epitope into the TM protein of $\mathrm{FV}$, the second question could be addressed by extended antigen delivery. This might be achieved in part by extended boosting as shown for a recombinant gp120 antigen inducing a limited degree of affinity maturation [9] or more efficiently by using replicating FV vectors which permanently express the antigen. Thus, after showing the general feasibility of using Bet/HIV-1 fusion proteins for induction of HIV-1 MPER specific antibodies, optimised hybrid proteins should now be expressed in replication-competent virus and the expression of the HIV epitopes monitored in infected eukaryotic cells. These replication-competent viruses may first be used in cats in order to analyse whether prolonged and systemic delivery of such proteins induce not only antibodies binding to epitopes overlapping with the 2F5 epitope, but also antibodies neutralising HIV-1. If successful, this would justify transfer to primate FV and testing in non-human primates.

\section{ACKNOWLEDGEMENTS}

This work was supported by the Volkswagenstiftung. We thank C.-M. Schmidt, M. Keller and D. Wirths for excellent technical support and A. Bleiholder for critical reading of the manuscript. All authors have approved the final article and declare that there is no conflict of interest.

\section{REFERENCES}

1. Burton DR, Weiss RA. AIDS/HIV. A boost for HIV vaccine design. Science. 2010;329(5993):770-3. doi:10.1126/science.1194693.

2. Mascola JR, Montefiori DC. The role of antibodies in HIV vaccines. Annu Rev Immunol. 2010;28:413-44. doi:10.1146/annurev-immunol-030409-101256.

3. Burton DR, Stanfield RL, Wilson IA. Antibody vs. HIV in a clash of evolutionary titans. Proc Natl Acad Sci U S A. 2005;102(42):14943-8. doi:10.1073/pnas.0505126102. 
4. Doria-Rose NA, Klein RM, Manion MM, O'Dell S, Phogat A, Chakrabarti B et al. Frequency and phenotype of human immunodeficiency virus envelope-specific B cells from patients with broadly cross-neutralizing antibodies. J Virol. 2009;83(1):188-99. doi:10.1128/JVI.01583-08.

5. Gray ES, Madiga MC, Hermanus T, Moore PL, Wibmer CK, Tumba NL et al. The neutralization breadth of HIV-1 develops incrementally over four years and is associated with CD4+ T cell decline and high viral load during acute infection. J Virol. 2011;85(10):4828-40. doi:10.1128/JVI.00198-11.

6. Haynes BF, Kelsoe G, Harrison SC, Kepler TB. B-cell-lineage immunogen design in vaccine development with HIV-1 as a case study. Nat Biotechnol. 2012;30(5):423-33. doi:10.1038/nbt.2197.

7. McMichael AJ, Borrow P, Tomaras GD, Goonetilleke N, Haynes BF. The immune response during acute HIV-1 infection: clues for vaccine development. Nat Rev Immunol. 2010;10(1):1123. doi:10.1038/nri2674.

8. Burton DR, Desrosiers RC, Doms RW, Koff WC, Kwong PD, Moore JP et al. HIV vaccine design and the neutralizing antibody problem. Nat Immunol. 2004;5(3):233-6. doi:10.1038/ni0304-233.

9. Moody MA, Yates NL, Amos JD, Drinker MS, Eudailey JA, Gurley TC et al. HIV-1 gp120 Vaccine Induces Affinity Maturation in both New and Persistent Antibody Clonal Lineages. J Virol. 2012;86(14):7496-507. doi:10.1128/JVI.00426-12.

10. Hansen SG, Ford JC, Lewis MS, Ventura AB, Hughes CM, Coyne-Johnson L et al. Profound early control of highly pathogenic SIV by an effector memory T-cell vaccine. Nature. 2011;473(7348):523-7. doi:10.1038/nature10003.

11. Hansen SG, Vieville C, Whizin N, Coyne-Johnson L, Siess DC, Drummond DD et al. Effector memory $\mathrm{T}$ cell responses are associated with protection of rhesus monkeys from mucosal simian immunodeficiency virus challenge. Nat Med. 2009;15(3):293-9. doi:10.1038/nm.1935.

12. Johnson RP, Desrosiers RC. Protective immunity induced by live attenuated simian immunodeficiency virus. Curr Opin Immunol. 1998;10(4):436-43.

13. Koff WC, Johnson PR, Watkins DI, Burton DR, Lifson JD, Hasenkrug KJ et al. HIV vaccine design: insights from live attenuated SIV vaccines. Nat Immunol. 2006;7(1):19-23. doi:10.1038/ni1296.

14. Picker LJ, Hansen SG, Lifson JD. New paradigms for HIV/AIDS vaccine development. Annual review of medicine. 2012;63:95-111. doi:10.1146/annurev-med-042010-085643.

15. Lindemann D, Rethwilm A. Foamy virus biology and its application for vector development. Viruses. 2011;3(5):561-85. doi:10.3390/v3050561.

16. Linial ML. Foamy viruses are unconventional retroviruses. J Virol. 1999;73(3):1747-55.

17. Rethwilm A. The replication strategy of foamy viruses. Curr Top Microbiol Immunol. 2003;277:1-26.

18. Trobridge GD, Miller DG, Jacobs MA, Allen JM, Kiem HP, Kaul R et al. Foamy virus vector integration sites in normal human cells. Proc Natl Acad Sci U S A. 2006;103(5):1498-503. doi:10.1073/pnas.0510046103.

19. Bauer TR, Jr., Olson EM, Huo Y, Tuschong LM, Allen JM, Li Y et al. Treatment of canine leukocyte adhesion deficiency by foamy virus vectors expressing CD18 from a PGK promoter. Gene Ther. 2011;18(6):553-9. doi:10.1038/gt.2010.169.

20. Erlwein O, McClure MO. Progress and prospects: foamy virus vectors enter a new age. Gene Ther. 2010;17(12):1423-9. doi:10.1038/gt.2010.95.

21. Taylor JA, Vojtech L, Bahner I, Kohn DB, Laer DV, Russell DW et al. Foamy virus vectors expressing anti-HIV transgenes efficiently block HIV-1 replication. Mol Ther. 2008;16(1):46-51. doi:10.1038/sj.mt.6300335.

22. Trobridge GD. Foamy virus vectors for gene transfer. Expert Opin Biol Ther. 2009;9(11):1427-36. doi:10.1517/14712590903246388.

23. Bastone P, Romen F, Liu W, Wirtz R, Koch U, Josephson N et al. Construction and characterization of efficient, stable and safe replication-deficient foamy virus vectors. Gene Ther. 2007;14(7):613-20. doi:3302890 [pii]

$10.1038 /$ sj.gt.3302890.

24. Schwantes A, Ortlepp I, Löchelt M. Construction and functional characterization of feline foamy virus-based retroviral vectors. Virology. 2002;301(1):53-63. doi:S0042682202915436 [pii]. 25. Schwantes A, Truyen U, Weikel J, Weiss C, Löchelt M. Application of chimeric feline foamy virus-based retroviral vectors for the induction of antiviral immunity in cats. J Virol. 2003;77(14):7830-42.

26. Zemba M, Alke A, Bodem J, Winkler IG, Flower RL, Pfrepper K et al. Construction of infectious feline foamy virus genomes: cat antisera do not cross-neutralize feline foamy virus 
chimera with serotype-specific Env sequences. Virology. 2000;266(1):150-6. doi:10.1006/viro.1999.0037

S0042682299900375 [pii].

27. Alke A, Schwantes A, Zemba M, Flügel RM, Löchelt M. Characterization of the humoral immune response and virus replication in cats experimentally infected with feline foamy virus. Virology. 2000;275(1):170-6. doi:10.1006/viro.2000.0537

S0042-6822(00)90537-3 [pii].

28. Bleiholder A, Mühle M, Hechler T, Bevins S, vandeWoude S, Denner J et al. Pattern of seroreactivity against feline foamy virus proteins in domestic cats from Germany. Vet Immunol Immunopathol. 2011;143(3-4):292-300. doi:10.1016/j.vetimm.2011.06.007.

29. Romen F, Pawlita M, Sehr P, Bachmann S, Schroder J, Lutz H et al. Antibodies against Gag are diagnostic markers for feline foamy virus infections while Env and Bet reactivity is undetectable in a substantial fraction of infected cats. Virology. 2006;345(2):502-8. doi:10.1016/j.virol.2005.10.022.

30. Giron ML, de The H, Saib A. An evolutionarily conserved splice generates a secreted env-Bet fusion protein during human foamy virus infection. J Virol. 1998;72(6):4906-10.

31. Lecellier $\mathrm{CH}$, Vermeulen W, Bachelerie F, Giron ML, Saib A. Intra- and intercellular trafficking of the foamy virus auxiliary bet protein. J Virol. 2002;76(7):3388-94.

32. Montero M, van Houten NE, Wang X, Scott JK. The membrane-proximal external region of the human immunodeficiency virus type 1 envelope: dominant site of antibody neutralization and target for vaccine design. Microbiol Mol Biol Rev. 2008;72(1):54-84, table of contents. doi:10.1128/MMBR.00020-07.

33. Muster T, Steindl F, Purtscher M, Trkola A, Klima A, Himmler G et al. A conserved neutralizing epitope on gp41 of human immunodeficiency virus type 1. J Virol. 1993;67(11):66427.

34. Salzwedel K, West JT, Hunter E. A conserved tryptophan-rich motif in the membraneproximal region of the human immunodeficiency virus type 1 gp41 ectodomain is important for Env-mediated fusion and virus infectivity. J Virol. 1999;73(3):2469-80.

35. Zwick MB, Labrijn AF, Wang M, Spenlehauer C, Saphire EO, Binley JM et al. Broadly neutralizing antibodies targeted to the membrane-proximal external region of human immunodeficiency virus type 1 glycoprotein gp41. J Virol. 2001;75(22):10892-905. doi:10.1128/JVI.75.22.10892-10905.2001.

36. Biron Z, Khare S, Samson AO, Hayek Y, Naider F, Anglister J. A monomeric 3(10)-helix is formed in water by a 13-residue peptide representing the neutralizing determinant of HIV-1 on gp41. Biochemistry. 2002;41(42):12687-96.

37. Bryson S, Julien JP, Isenman DE, Kunert R, Katinger H, Pai EF. Crystal structure of the complex between the $\mathrm{F}(\mathrm{ab})^{\prime}$ fragment of the cross-neutralizing anti-HIV-1 antibody $2 \mathrm{~F} 5$ and the $\mathrm{F}(\mathrm{ab})$ fragment of its anti-idiotypic antibody 3H6. J Mol Biol. 2008;382(4):910-9. doi:10.1016/j.jmb.2008.07.057.

38. Buzon V, Natrajan G, Schibli D, Campelo F, Kozlov MM, Weissenhorn W. Crystal structure of HIV-1 gp41 including both fusion peptide and membrane proximal external regions. PLoS Pathog. 2010;6(5):e1000880. doi:10.1371/journal.ppat.1000880.

39. Ofek G, Tang M, Sambor A, Katinger H, Mascola JR, Wyatt R et al. Structure and mechanistic analysis of the anti-human immunodeficiency virus type 1 antibody 2 F5 in complex with its gp41 epitope. J Virol. 2004;78(19):10724-37. doi:10.1128/JVI.78.19.10724-10737.2004.

40. Schibli DJ, Montelaro RC, Vogel HJ. The membrane-proximal tryptophan-rich region of the HIV glycoprotein, gp41, forms a well-defined helix in dodecylphosphocholine micelles. Biochemistry. 2001;40(32):9570-8.

41. Sun ZY, Oh KJ, Kim M, Yu J, Brusic V, Song L et al. HIV-1 broadly neutralizing antibody extracts its epitope from a kinked gp41 ectodomain region on the viral membrane. Immunity. 2008;28(1):52-63. doi:10.1016/j.immuni.2007.11.018.

42. Alam SM, Morelli M, Dennison SM, Liao HX, Zhang R, Xia SM et al. Role of HIV membrane in neutralization by two broadly neutralizing antibodies. Proc Natl Acad Sci U S A. 2009;106(48):20234-9. doi:10.1073/pnas.0908713106.

43. Scherer EM, Leaman DP, Zwick MB, McMichael AJ, Burton DR. Aromatic residues at the edge of the antibody combining site facilitate viral glycoprotein recognition through membrane interactions. Proc Natl Acad Sci U S A. 2010;107(4):1529-34. doi:10.1073/pnas.0909680107.

44. Julien JP, Bryson S, Nieva JL, Pai EF. Structural details of HIV-1 recognition by the broadly neutralizing monoclonal antibody 2F5: epitope conformation, antigen-recognition loop mobility, and anion-binding site. J Mol Biol. 2008;384(2):377-92. doi:10.1016/j.jmb.2008.09.024. 
45. Coeffier E, Clement JM, Cussac V, Khodaei-Boorane N, Jehanno M, Rojas M et al. Antigenicity and immunogenicity of the HIV-1 gp41 epitope ELDKWA inserted into permissive sites of the MalE protein. Vaccine. 2000;19(7-8):684-93.

46. Ho J, MacDonald KS, Barber BH. Construction of recombinant targeting immunogens incorporating an HIV-1 neutralizing epitope into sites of differing conformational constraint. Vaccine. 2002;20(7-8):1169-80.

47. Ho J, Uger RA, Zwick MB, Luscher MA, Barber BH, MacDonald KS. Conformational constraints imposed on a pan-neutralizing HIV-1 antibody epitope result in increased antigenicity but not neutralizing response. Vaccine. 2005;23(13):1559-73. doi:10.1016/j.vaccine.2004.09.037.

48. McGaughey GB, Citron M, Danzeisen RC, Freidinger RM, Garsky VM, Hurni WM et al. HIV-1 vaccine development: constrained peptide immunogens show improved binding to the antiHIV-1 gp41 MAb. Biochemistry. 2003;42(11):3214-23. doi:10.1021/bi026952u.

49. Brunel FM, Zwick MB, Cardoso RM, Nelson JD, Wilson IA, Burton DR et al. Structurefunction analysis of the epitope for 4E10, a broadly neutralizing human immunodeficiency virus type 1 antibody. J Virol. 2006;80(4):1680-7. doi:10.1128/JVI.80.4.1680-1687.2006.

50. Cardoso RM, Brunel FM, Ferguson S, Zwick M, Burton DR, Dawson PE et al. Structural basis of enhanced binding of extended and helically constrained peptide epitopes of the broadly neutralizing HIV-1 antibody 4E10. J Mol Biol. 2007;365(5):1533-44. doi:10.1016/j.jmb.2006.10.088.

51. Cardoso RM, Zwick MB, Stanfield RL, Kunert R, Binley JM, Katinger H et al. Broadly neutralizing anti-HIV antibody 4E10 recognizes a helical conformation of a highly conserved fusion-associated motif in gp41. Immunity. 2005;22(2):163-73. doi:10.1016/j.immuni.2004.12.011.

52. Bellamy-McIntyre AK, Lay CS, Baar S, Maerz AL, Talbo GH, Drummer HE et al. Functional links between the fusion peptide-proximal polar segment and membrane-proximal region of human immunodeficiency virus gp41 in distinct phases of membrane fusion. J Biol Chem. 2007;282(32):23104-16. doi:10.1074/jbc.M703485200.

53. Fiebig U, Schmolke M, Eschricht M, Kurth R, Denner J. Mode of interaction between the HIV-1-neutralizing monoclonal antibody 2F5 and its epitope. AIDS. 2009;23(8):887-95. doi:10.1097/QAD.0b013e3283292153.

54. Lorizate M, Gomara MJ, de la Torre BG, Andreu D, Nieva JL. Membrane-transferring sequences of the HIV-1 Gp41 ectodomain assemble into an immunogenic complex. J Mol Biol. 2006;360(1):45-55. doi:10.1016/j.jmb.2006.04.056.

55. Noah E, Biron Z, Naider F, Arshava B, Anglister J. The membrane proximal external region of the HIV-1 envelope glycoprotein gp41 contributes to the stabilization of the six-helix bundle formed with a matching N' peptide. Biochemistry. 2008;47(26):6782-92. doi:10.1021/bi7023139.

56. de la Arada I, Julien JP, de la Torre BG, Huarte N, Andreu D, Pai EF et al. Structural constraints imposed by the conserved fusion peptide on the HIV -1 gp41 epitope recognized by the broadly neutralizing antibody 2F5. J Phys Chem B. 2009;113(41):13626-37. doi:10.1021/jp905965h.

57. Lorizate M, de la Arada I, Huarte N, Sanchez-Martinez S, de la Torre BG, Andreu D et al. Structural analysis and assembly of the HIV-1 Gp41 amino-terminal fusion peptide and the pretransmembrane amphipathic-at-interface sequence. Biochemistry. 2006;45(48):14337-46. doi:10.1021/bi0612521.

58. Mühle M, Löchelt M, Denner J. Optimisation of expression and purification of the feline and primate foamy virus transmembrane envelope proteins using a 96 deep well screen. Protein Expr Purif. 2012;81(1):96-105. doi:10.1016/j.pep.2011.09.006.

59. Frey A, Di Canzio J, Zurakowski D. A statistically defined endpoint titer determination method for immunoassays. J Immunol Methods. 1998;221(1-2):35-41. doi:S0022-1759(98)001707 [pii].

60. Mühle M, Bleiholder A, Kolb S, Hübner J, Löchelt M, Denner J. Immunological properties of the transmembrane envelope protein of the feline foamy virus and its use for serological screening. Virology. 2011;412(2):333-40. doi:10.1016/j.virol.2011.01.023.

61. Fezoui Y, Weaver DL, Osterhout JJ. De novo design and structural characterization of an alpha-helical hairpin peptide: a model system for the study of protein folding intermediates. Proc Natl Acad Sci U S A. 1994;91(9):3675-9.

62. Fezoui Y, Connolly PJ, Osterhout JJ. Solution structure of alpha $t$ alpha, a helical hairpin peptide of de novo design. Protein Sci. 1997;6(9):1869-77. doi:10.1002/pro.5560060907.

63. Gallo SA, Finnegan CM, Viard M, Raviv Y, Dimitrov A, Rawat SS et al. The HIV Envmediated fusion reaction. Biochim Biophys Acta. 2003;1614(1):36-50.

64. Zwick MB, Jensen R, Church S, Wang M, Stiegler G, Kunert R et al. Anti-human immunodeficiency virus type 1 (HIV-1) antibodies 2 F5 and 4E10 require surprisingly few crucial 
residues in the membrane-proximal external region of glycoprotein gp41 to neutralize HIV-1. J Virol. 2005;79(2):1252-61. doi:10.1128/JVI.79.2.1252-1261.2005.

65. Frey G, Chen J, Rits-Volloch S, Freeman MM, Zolla-Pazner S, Chen B. Distinct conformational states of HIV-1 gp41 are recognized by neutralizing and non-neutralizing antibodies. Nature structural \& molecular biology. 2010;17(12):1486-91. doi:10.1038/nsmb.1950.

66. Frey G, Peng H, Rits-Volloch S, Morelli M, Cheng Y, Chen B. A fusion-intermediate state of HIV-1 gp41 targeted by broadly neutralizing antibodies. Proc Natl Acad Sci U S A. 2008;105(10):3739-44. doi:10.1073/pnas.0800255105.

67. Zhu Z, Qin HR, Chen W, Zhao Q, Shen X, Schutte R et al. Cross-reactive HIV-1-neutralizing human monoclonal antibodies identified from a patient with 2F5-like antibodies. J Virol. 2011;85(21):11401-8. doi:10.1128/JVI.05312-11.

68. Guenaga J, Dosenovic P, Ofek G, Baker D, Schief WR, Kwong PD et al. Heterologous epitope-scaffold prime:boosting immuno-focuses B cell responses to the HIV-1 gp41 2F5 neutralization determinant. PLoS One. 2011;6(1):e16074. doi:10.1371/journal.pone.0016074.

69. Ofek G, Guenaga FJ, Schief WR, Skinner J, Baker D, Wyatt R et al. Elicitation of structurespecific antibodies by epitope scaffolds. Proc Natl Acad Sci U S A. 2010;107(42):17880-7. doi:10.1073/pnas.1004728107.

70. McGaughey GB, Barbato G, Bianchi E, Freidinger RM, Garsky VM, Hurni WM et al. Progress towards the development of a HIV-1 gp41-directed vaccine. Curr HIV Res. 2004;2(2):193-204.

71. Wang J, Tong P, Lu L, Zhou L, Xu L, Jiang S et al. HIV-1 gp41 core with exposed membraneproximal external region inducing broad HIV-1 neutralizing antibodies. PLoS One. 2011;6(3):e18233. doi:10.1371/journal.pone.0018233.

72. Garrity RR, Rimmelzwaan G, Minassian A, Tsai WP, Lin G, de Jong JJ et al. Refocusing neutralizing antibody response by targeted dampening of an immunodominant epitope. J Immunol. 1997;159(1):279-89.

\section{FIGURE LEGENDS}

Fig. 1 Schematic presentation of gp41 of HIV-1 (a) and of FFV Bet and the FFV Bet/HIV-1 fusion proteins used for immunisation (b). FP - fusion peptide, FPPR - fusion peptide proximal region, NHR/CHR - N-terminal and C-terminal helical region, MPER - membrane proximal external region, MSD - membrane spanning domain, $\mathrm{C}-\mathrm{C}$ - cysteine loop, TM - transmembrane envelope protein, His - Histidine tag, Factor Xa - Factor Xa protease cleavage site, Bet - full length FFV Bet sequence, Linker - 4 (FFV Bet) or 15 (all other constructs) amino acid spacer. E1 - HIV-1 FPPR-derived domain, E2 - HIV-1 MPER-derived domain, E1-E2, HIV-1 E1 and E2 domains connected by a flexible loop sequence. The theoretical molecular mass of all antigens is indicated. Lines below the E2 sequence of gp41 of HIV-1 mark the location of the neutralising epitopes of 2F5 and 4E10. (c) Purity of the produced antigens. $2 \mu \mathrm{g}$ of recombinant proteins were loaded for SDS-PAGE and stained by Coomassie blue. The molecular mass of the marker are indicated. (d) Recognition of the produced antigens by the monoclonal antibodies 2F5 and 4E10 and a FPPR specific antiserum. $150 \mathrm{ng}$ of recombinant proteins were transferred onto a PVDF membrane and tested with the antibodies $2 \mathrm{~F} 5(0.4 \mu \mathrm{g} / \mathrm{ml}), 4 \mathrm{E} 10(1.2 \mu \mathrm{g} / \mathrm{ml})$ and an E1 specific rat serum $(1: 800)$ to confirm the presence of the corresponding HIV-1 domains

Fig. 2 Recognition of the produced antigens by the monoclonal antibodies 2F5 and 4E10 under non-denaturing conditions in an ELISA. $100 \mathrm{ng}$ of indicated Bet/HIV-1 antigens in phosphate buffer were coated and incubated with $2 \mathrm{~F} 5(11.3 \mu \mathrm{g} / \mu \mathrm{l})$ or $4 \mathrm{E} 10(11.9 \mu \mathrm{g} / \mu \mathrm{l})$ serially diluted as indicated, followed by detection with an HRP anti-human IgG antibody and developed with OPD. Whereas only minor differences of $2 \mathrm{~F} 5$ binding were detected, threefold increased binding of 4E10 to the FPPR stabilised Bet-E1-E2 protein was found 
Fig. 3 Titers of the immune sera after immunisation with Bet fusion proteins as determined by endpoint dilutions. (a) Sera from rat group 364 immunised with Bet-E1, (b) from group 365 immunised with Bet-E2, (c-d) from group 366 immunised with both Bet/HIV-1 hybrid antigens (e) and from group 375 immunised with Bet-E1-E2. PI = pre-immune serum, 1, 2, $3=$ serum of the first, second and third bleeding, respectively

Fig. 4 Reactivity of sera from animals immunised with the hybrid proteins against gp41 and synthetic E1 and E2 peptides as measured in an ELISA. Sera were serially diluted in a range of $10^{2}$ to $10^{7}$. The endpoint titers of (a) sera from rat group 364 , (b) sera from rat group 365 , (c, d) sera from rat groups 366 and 375, all titrated against the E1 and/or E2 peptides as well as recombinant gp41, are given. The administered antigen is indicated in brackets

Fig. 5 Epitope mapping of the sera from immunised animals. Microarrays spotted with overlapping 15 mer peptides of the prolonged HIV-1 FPPR and MPER domains were incubated with antisera and bound antibodies detected by a fluorescent secondary anti-rat antibody. Results are plotted as relative light units (RLU) against the individual FPPR and MPER peptides. The group number, the administered antigen and the recognised epitopes as defined as central amino acids shared by overlapping peptides exceeding a 5000 RLU intensity threshold (grey line) are indicated. As internal control anti rat IgG spotted on the slides were measured in parallel

Fig. 6 Binding of induced antisera to HIV-1 pNL-4.3 infected C8166 cells. (a) Analysis of antibody binding by flow cytometry $72 \mathrm{~h}$ after infection. Cells were probed with pre-immune rat serum (PI) or antisera from a representative animal from the rat group immunised with the antigen indicated above. (b) Indirect immunofluorescence of C8166 cells $48 \mathrm{~h}$ after of infection. Fixed cells were transferred to slides where they were incubated with the same sera as in (a). Rat IgGs were detected by an Alexa-Fluor 488 antibody and analysed at a magnification of 20x (upper panel) or 60x (lower panel). No reactivity was observed for the control (Ctrl), but antisera showed either diffuse staining when containing FPPR-targeting antibodies (rats 364) or distinct spots predominantly on the cell surface in antisera where MPER directed antibodies were present (rats $365,366,375)$

Online Resource 1 Design and bioinformatic characterisation of the E1-E2 antigen. (a) Amino acid sequence of E1-E2 and individual domains. The fusion peptide proximal region (FPPR), the membrane proximal external region (MPER), the alpha helical flanking regions $(\alpha)$ and the $\beta$-turn loop element (L) are shown. (b) Chou-Fasman secondary structure predictions for the E1-E2 antigen, plotting the probability score to form alpha helices (left diagram) or beta-turns (right diagram) against individual amino acids. Note the distinct structural break at amino acids 30-34, representing the loop element. Graphs were obtained with the ProtScale software provided on the expasy proteomics server (http://web.expasy.org/protscale). (c) Model of E1-E2 interaction and positioning of FPPR and MPER contacting amino acids. The 15 amino acid linker and the Bet fusion partner are schematically shown (d) Alpha helical wheel projections of both domains with the positioning of critical residues as in (b) indicated by circles. Projections were made with the help of the Wheel program provided by Don Armstrong (http://trimer.tamu.edu/cgibin/wheel/wheel.pl)

Online Resource 2 Surface plasmon resonance experiments with the antigens used for immunisation and the antibodies $2 \mathrm{~F} 5$ and 4E10. The signal intensity in response units (RU), the protein concentrations (in $\mathrm{nM}$ ), protein and buffer injection points (black and grey arrows) and calculated $\mathrm{K}_{\mathrm{D}}$ values are indicated for interactions measured with captured $2 \mathrm{~F} 5$ antibody and Bet$\mathrm{E} 1$, Bet-E2, Bet-E1+ Bet-E2 and Bet-E1-E2 or for interaction measured with captured 4E10 antibody and the Bet-E1-E2 antigen. Response curves are shown as grey lines, fitted curves are in black. Note that response peaks between individual injections (arrows) correspond to bulk contributions as a result of differences in the buffer composition 
Online Resource 3 Western blot analysis of antisera of the final bleeding using purified recombinant gp41 as antigen (200 ng gp41/lane). Antisera (1:1000) were incubated on the membrane using a slot blot chamber and an anti-rat HRP-labelled secondary antibody for detection. The number of the animals is indicated. $2 \mathrm{~F} 5$ was used as positive control $(113 \mathrm{ng} / \mathrm{ml})$

Online Resource 4 Neutralisation assays based on TZM-bl cells and titrated HIV-pNL-4.3. Virus was incubated for $30 \mathrm{~min}$ at $37^{\circ} \mathrm{C}$ with either $2 \mathrm{~F} 5(25,12.5,6.25$ and $3.12 \mu \mathrm{g} / \mathrm{ml}$, positive control), pre-immune sera (PI) or immune sera (1:50) of the indicated animal group (364-375), animal number (\#1-4) and bleeding and then added to TZM-bl cells plated one day in advance. $48 \mathrm{~h}$ after assay setup, cells were stained for infection with X-gal and colonies counted using an ELISPOTreader. Neutralisation was defined as $50 \%$ reduction of stained cells when immune sera and preimmune sera were compared. Whereas 2F5 was effectively neutralising, none of the immune sera achieved reduction of viral infection by more than $50 \%$

Online Resource 5 Endpoint titres of antisera titrated against antigens used for immunisation

Online Resource 6 Endpoint titres of antisera titrated against HIV-1 domains and recombinant gp41 


\section{Mühle et al., Figure 1}

a

HIV-1 gp41

b
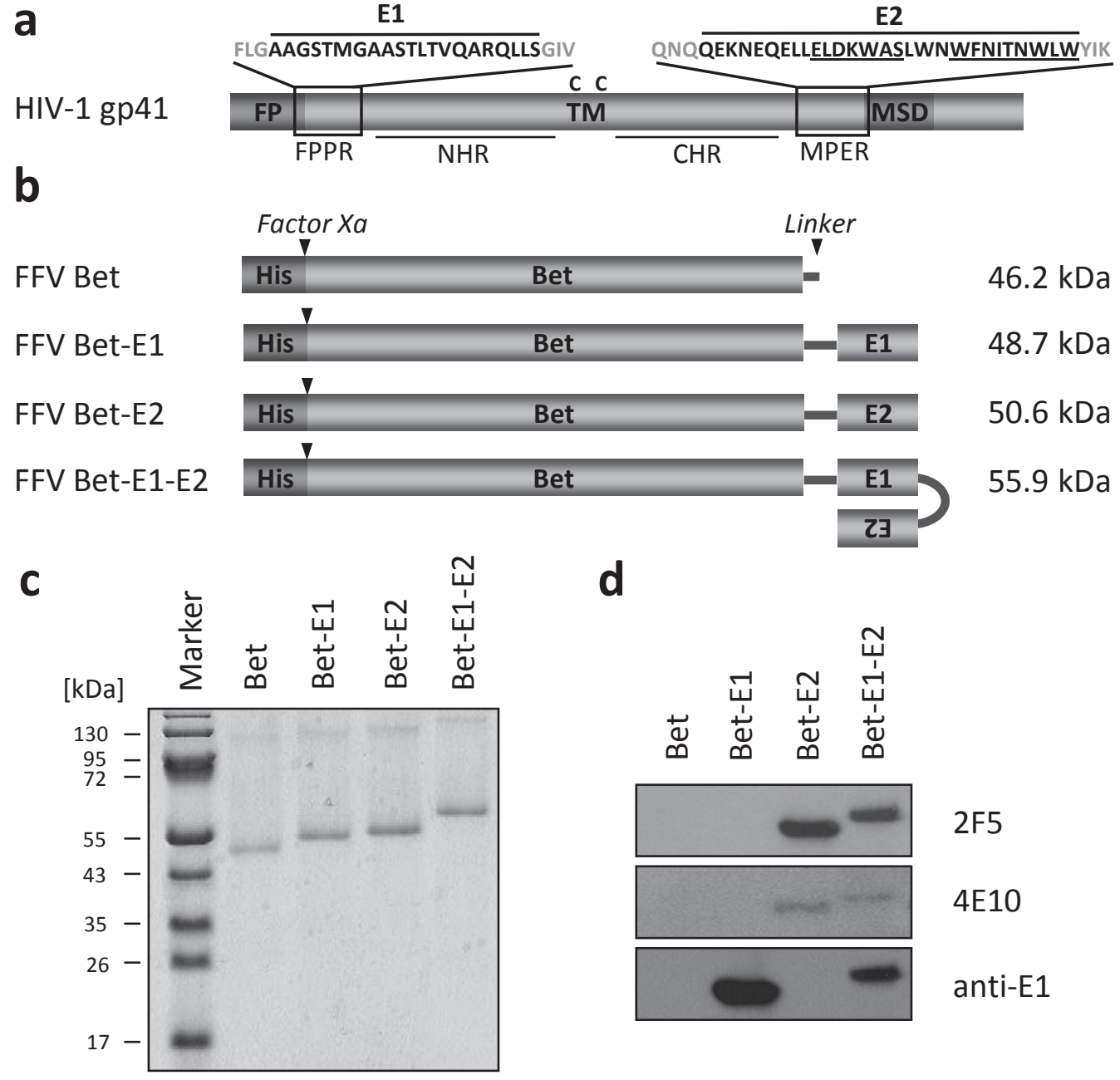

d

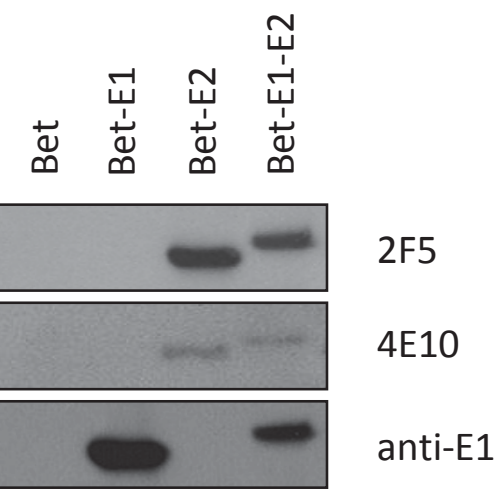




\section{Mühle et al., Figure 2}
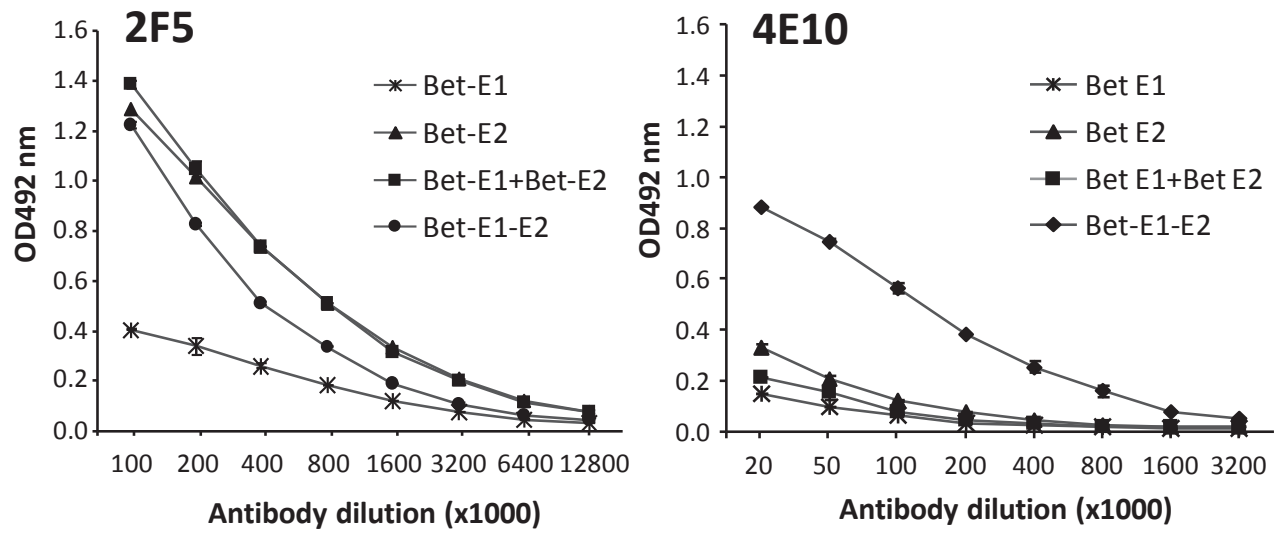
Mühle et al., Figure 3
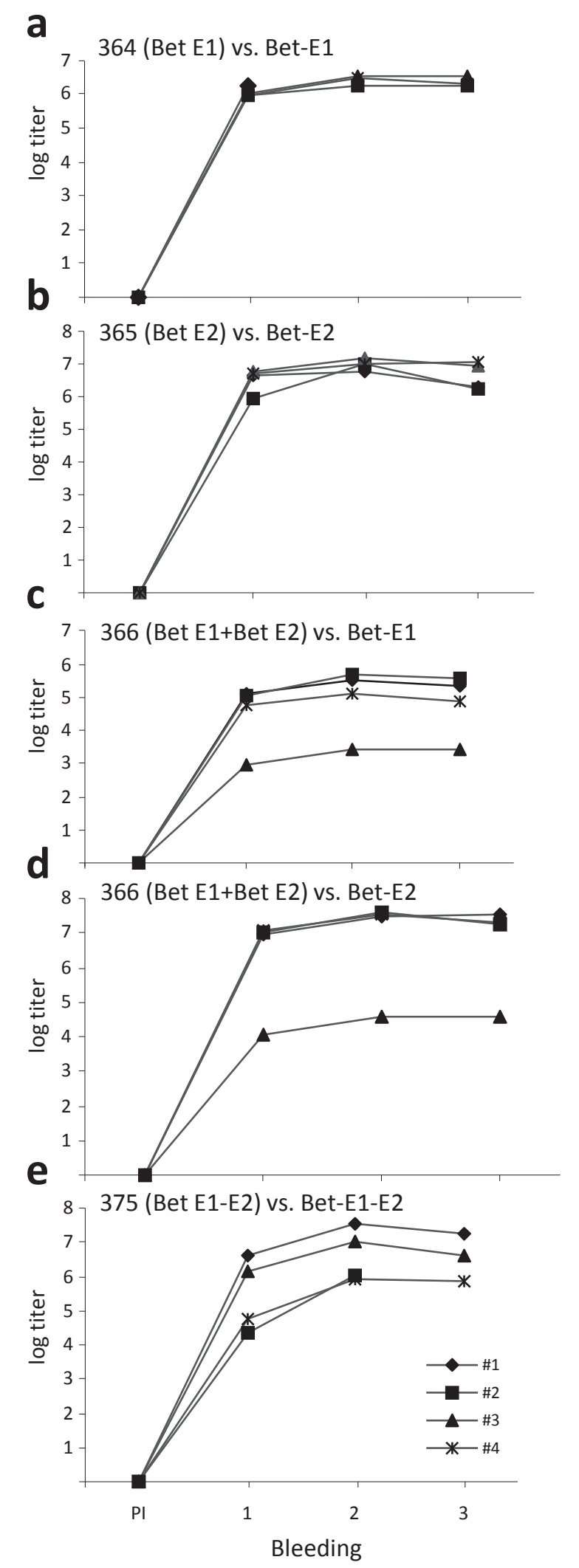
Mühle et al., Figure 4

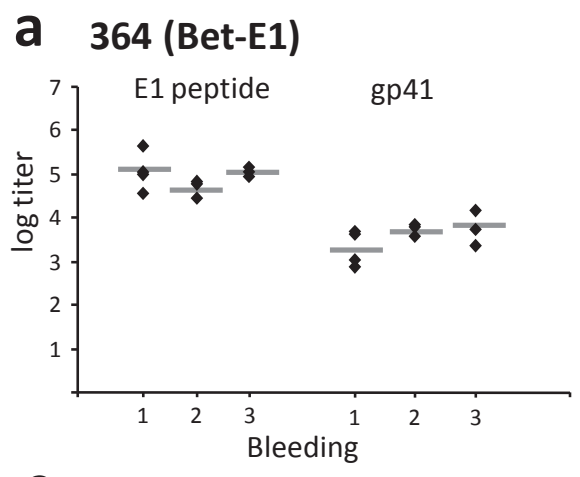

C 366 (Bet-E1+Bet-E2)

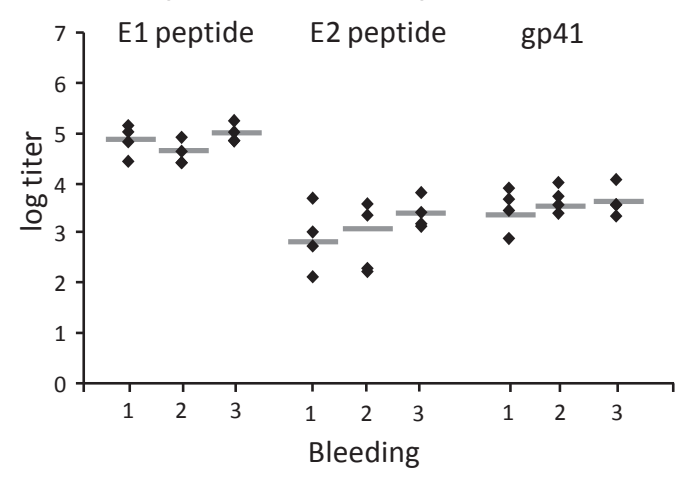

b 365 (Bet-E2)

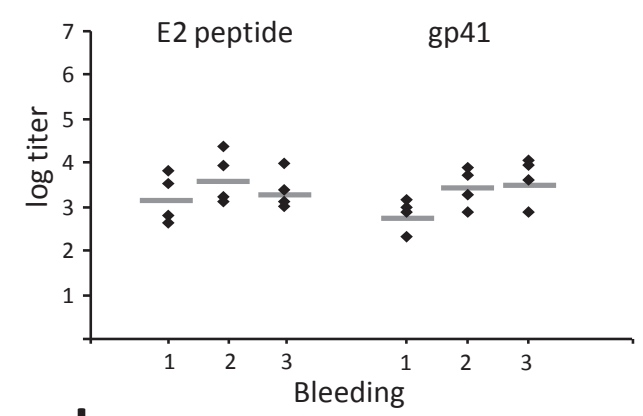

d 375 (Bet-E1-E2)

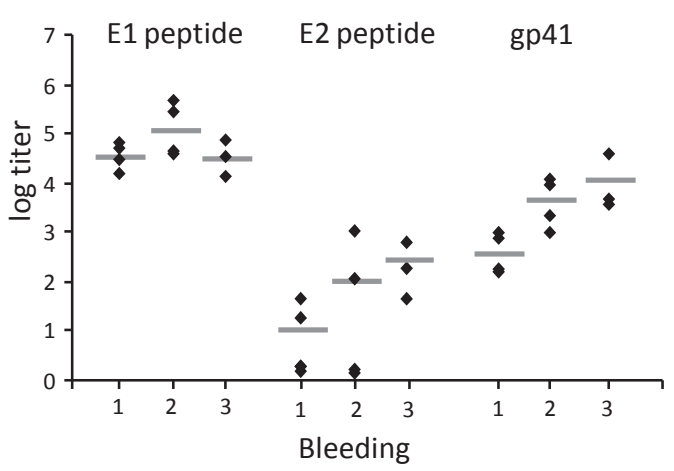




\section{Mühle et al., Figure 5}

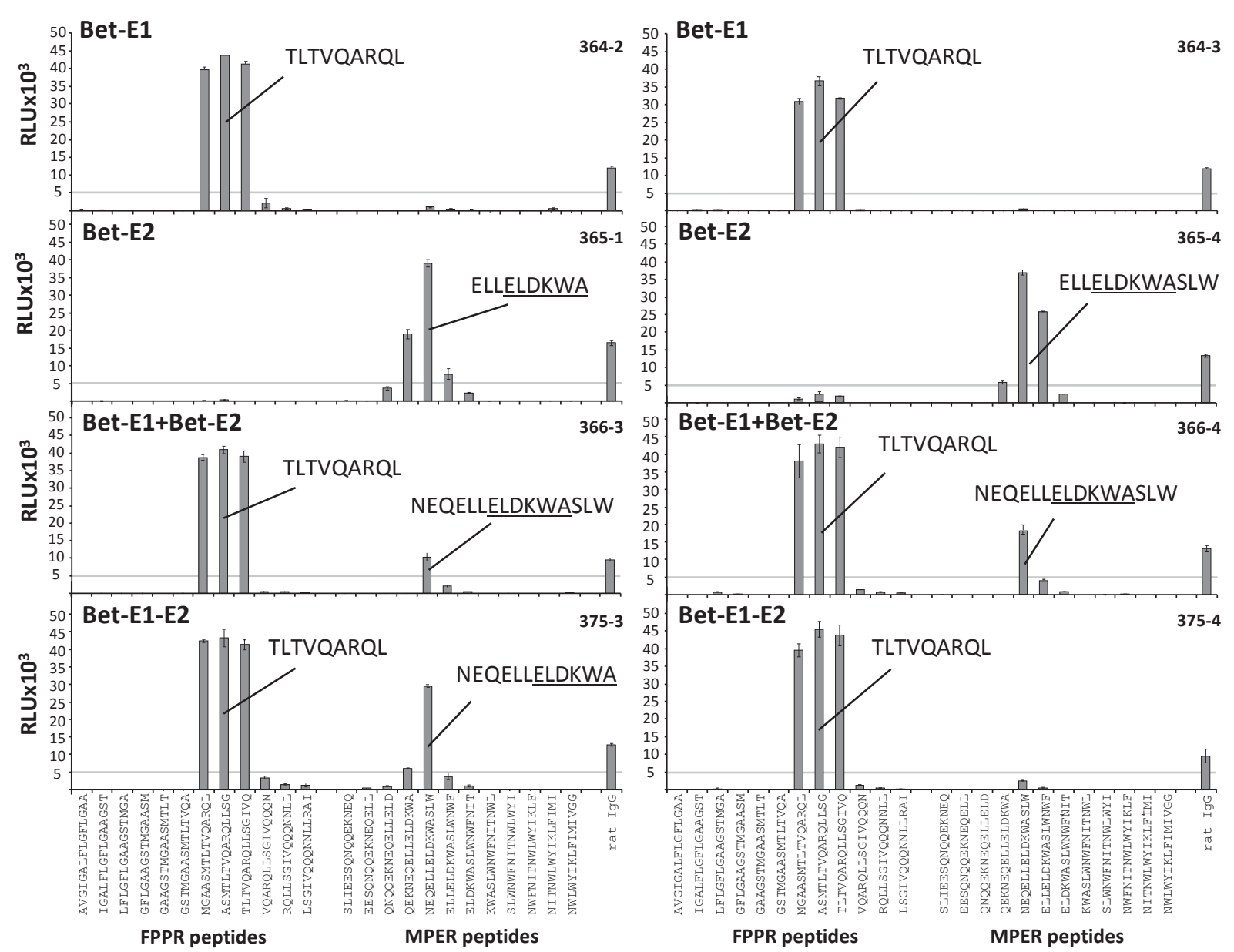


Mühle et al., Figure 6
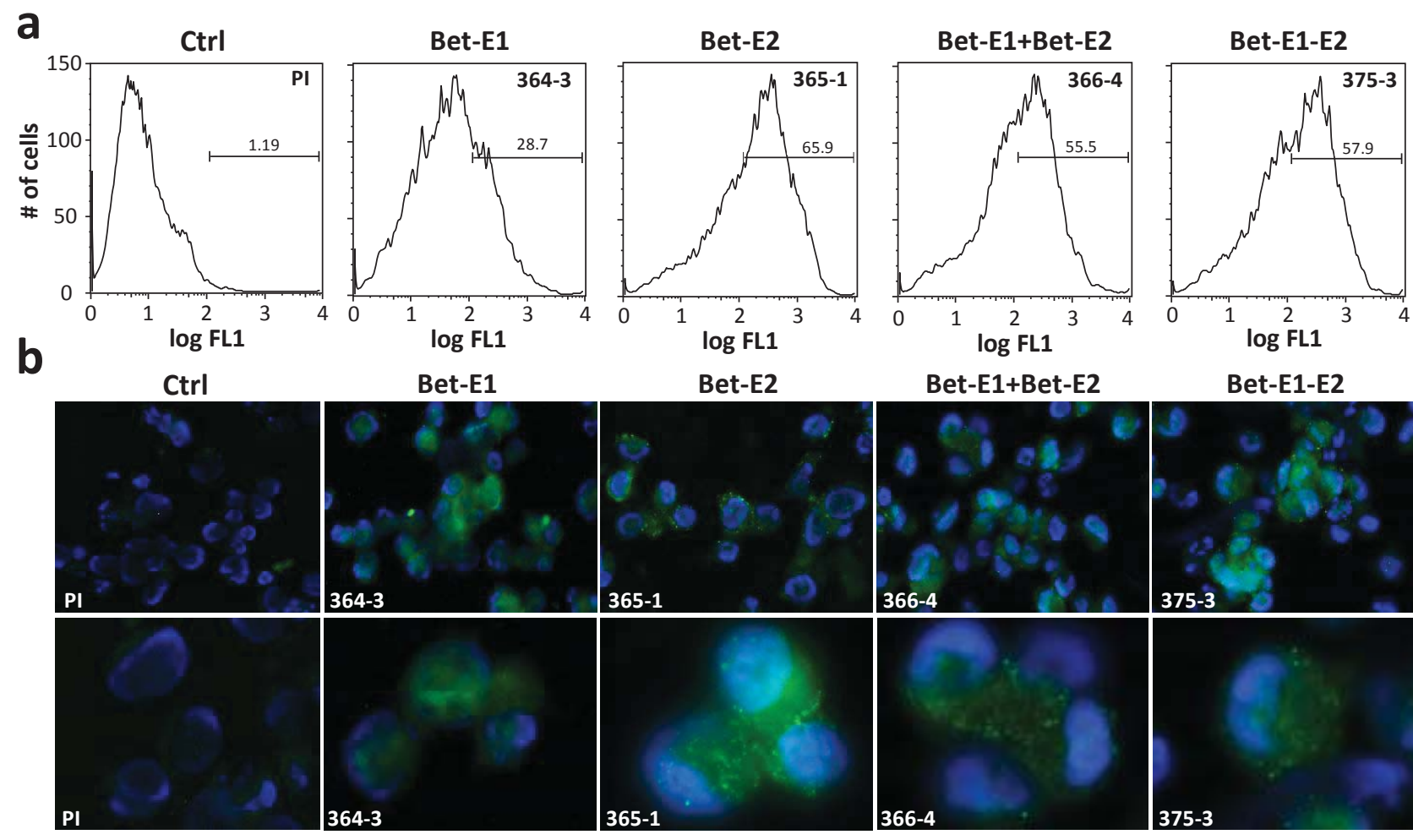

Bet-E1+Bet-E2

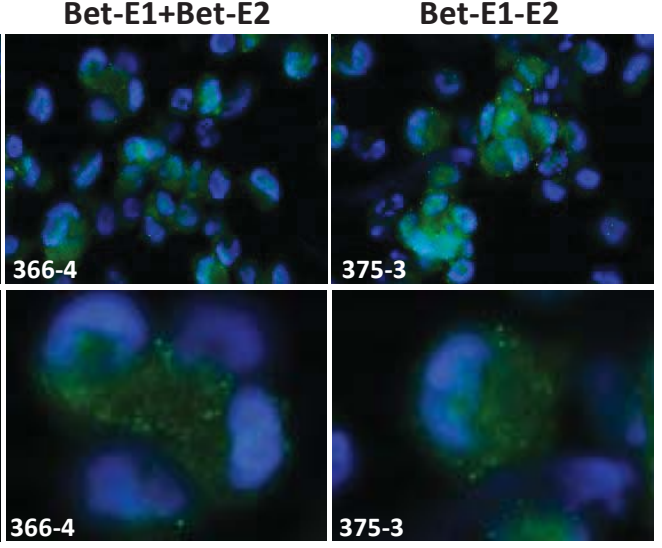


Table 1 Kinetic constants determined by SPR measurements.

\begin{tabular}{llccc} 
Analyt & Ligand & $\mathrm{k}_{\mathrm{on}}\left[1 / \mathrm{M} *_{\mathrm{S}}\right]$ & $\mathrm{k}_{\mathrm{off}}[1 / \mathrm{s}]$ & $\mathrm{K}_{\mathrm{D}}[\mathrm{M}]$ \\
\hline Bet-E1 & $2 \mathrm{~F} 5$ & $-^{\mathrm{a}}$ & - & - \\
Bet-E2 & $2 \mathrm{~F} 5$ & $2,01 \times 10^{4}$ & $8,60 \times 10^{-5}$ & $4,28 \times 10^{-9}$ \\
Bet-E1+Bet-E2 & $2 \mathrm{~F} 5$ & $1,93 \times 10^{4}$ & $1,14 \times 10^{-4}$ & $5,91 \times 10^{-9}$ \\
Bet-E1-E2 & $2 \mathrm{~F} 5$ & $1,07 \times 10^{4}$ & $2,07 \times 10^{-4}$ & $1,93 \times 10^{-8}$ \\
& & & & - \\
Bet-E1 & 4E10 & - & n.d. & n.d. \\
Bet-E2 & 4E10 & n.d. & n.d. & n.d. \\
Bet-E1+Bet-E2 & 4E10 & n.d. & $4,66 \times 10^{-4}$ & $2,24 \times 10^{-7}$ \\
Bet-E1-E2 & 4E10 & $2,08 \times 10^{3}$ & & \\
\hline
\end{tabular}

${ }^{\mathrm{a}}$ no interaction observed

${ }^{\mathrm{b}}$ not determinable due to protein concentration limitations 


\title{
Immunisation with foamy virus Bet fusion proteins as novel strategy for HIV-1 epitope delivery. Immunologic Research,
}

\author{
M. Mühle, K. Hoffmann, M. Löchelt, J. Denner
}

\section{Online Resource 1}

a

\begin{tabular}{ccccc} 
FPPR & $\boldsymbol{\alpha}$ & $\mathbf{L}$ & $\boldsymbol{\alpha}$ & MPER \\
\cline { 2 - 3 }
\end{tabular}

b
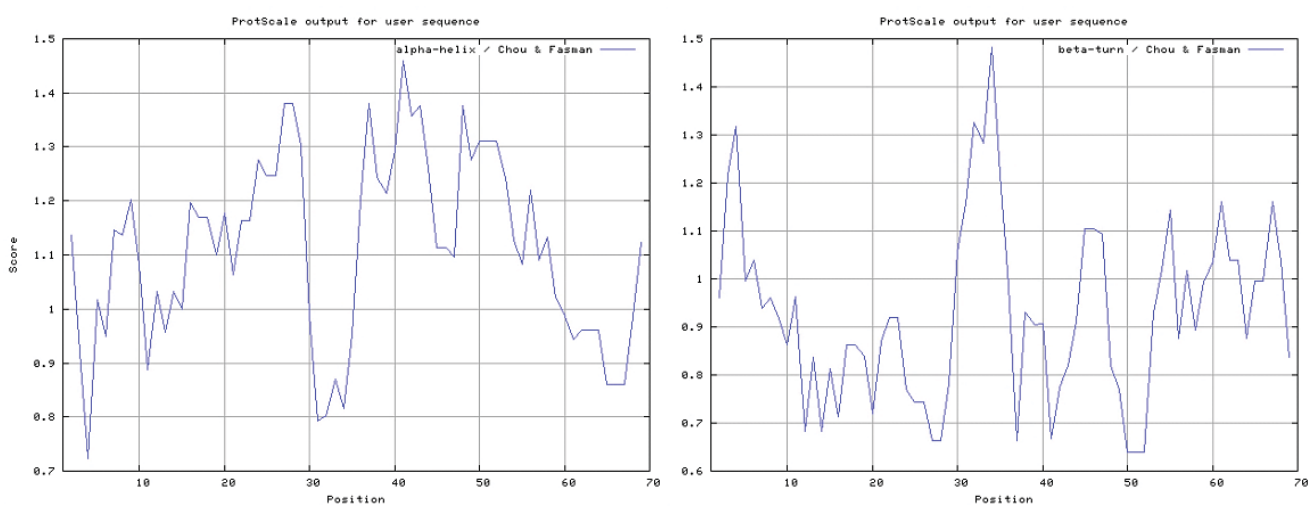

C

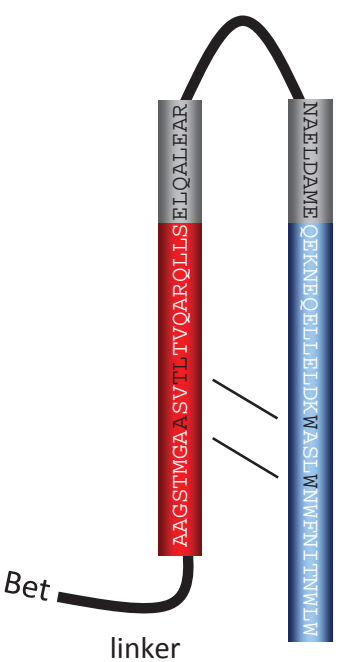

d

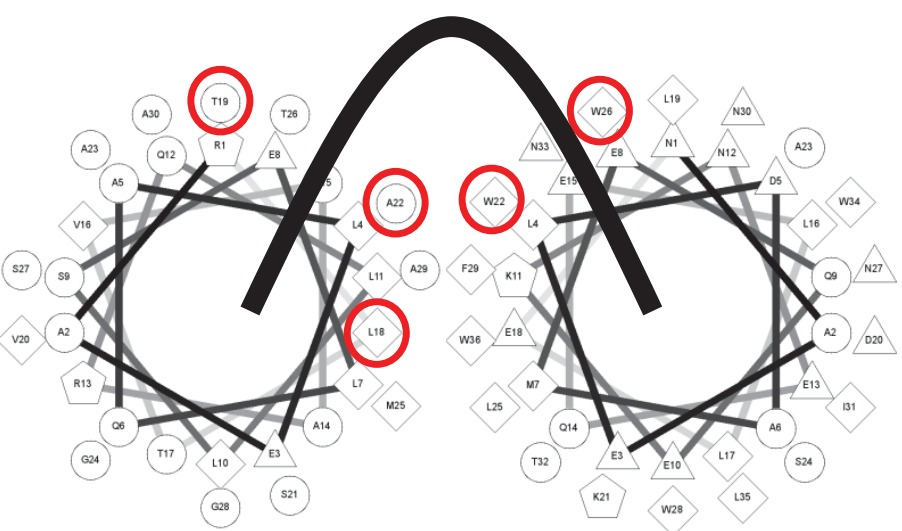

Design and bioinformatic characterisation of the E1-E2 antigen. (a) Amino acid sequence of E1-E2 and individual domains. The fusion peptide proximal region (FPPR), the membrane proximal external region (MPER), the alpha helical flanking regions $(\alpha)$ and the $\beta$-turn loop element $(L)$ are shown. (b) Chou-Fasman secondary structure predictions for the E1-E2 antigen, plotting the probability score to form alpha helices (left diagram) or beta-turns (right diagram) against individual amino acids. Note the distinct structural break at amino acids 3034, representing the loop element. Graphs were obtained with the ProtScale software provided on the expasy proteomics server (http://web.expasy.org/protscale). (c) Model of E1-E2 interaction and positioning of FPPR and MPER contacting amino acids. The 15 amino acid linker and the Bet fusion partner are schematically shown (d) Alpha helical wheel projections of both domains with the positioning of critical residues as in (b) indicated by circles. Projections were made with the help of the Wheel program provided by Don Armstrong (http://trimer.tamu.edu/cgi-bin/wheel/wheel.pl) 


\title{
Immunisation with foamy virus Bet fusion proteins as novel \\ strategy for HIV-1 epitope delivery. Immunologic Research,
}

\author{
M. Mühle, K. Hoffmann, M. Löchelt, J. Denner
}

\section{Online Resource 2}
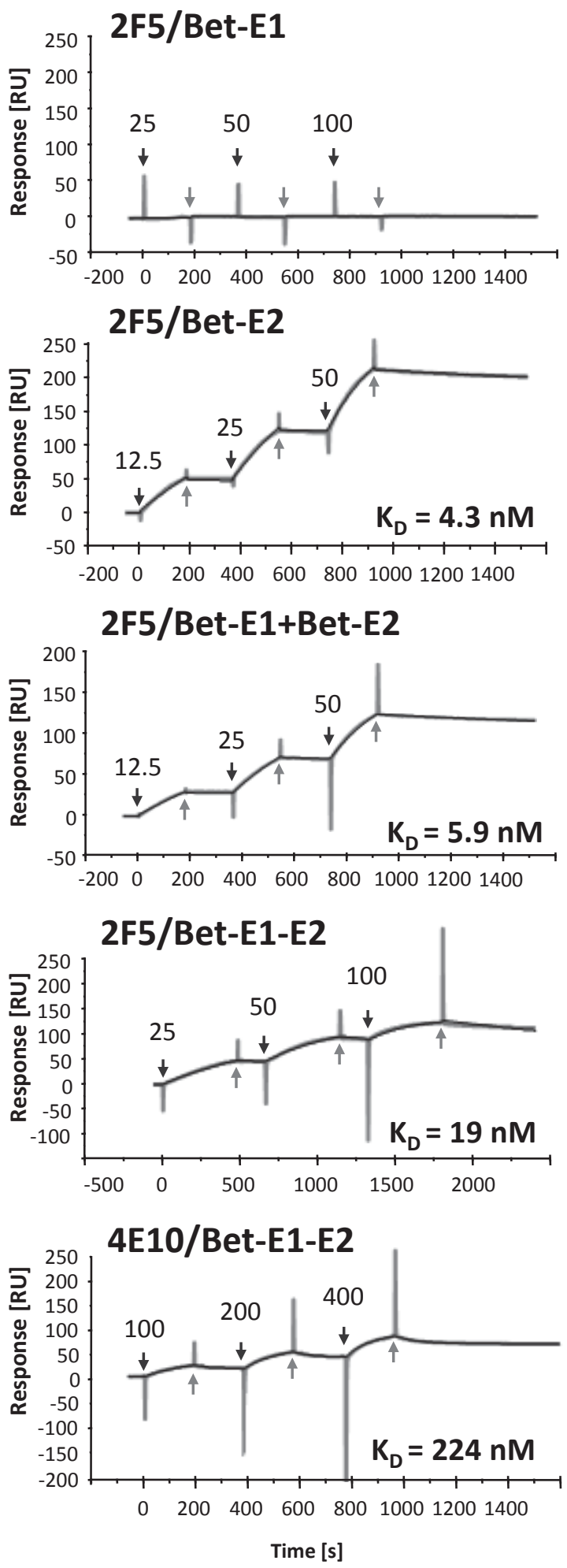

Surface plasmon resonance experiments with the antigens used for immunisation and the antibodies 2F5 and 4E10. The signal intensity in response units (RU), the protein concentrations (in $\mathrm{nM}$ ), protein and buffer injection points (black and grey arrows) and calculated $\mathrm{K}_{\mathrm{D}}$ values are indicated for interactions measured with captured 2F5 antibody and Bet-E1, Bet-E2, Bet-E1+ Bet-E2 and Bet-E1-E2 or for interaction measured with captured 4E10 antibody and the Bet-E1-E2 antigen. Response curves are shown as grey lines, fitted curves are in black. Note that response peaks between individual injections (arrows) correspond to bulk contributions as a result of differences in the buffer composition 
Immunisation with foamy virus Bet fusion proteins as novel strategy for HIV-1 epitope delivery. Immunologic Research, M. Mühle, K. Hoffmann, M. Löchelt, J. Denner

Online Resource 3 Endpoint titres of antisera titrated against antigens used for immunisation

\begin{tabular}{|c|c|c|c|c|}
\hline Rat No. & Tested antigen & 1st bleeding & 2nd bleeding & 3rd bleeding \\
\hline $364-1$ & Bet E1 & $1.77 \times 10^{6}$ & n.a. & n.a. \\
\hline $364-2$ & & $9.32 \times 10^{5}$ & $1.81 \times 10^{6}$ & $1.64 \times 10^{6}$ \\
\hline $364-3$ & & $1.03 \times 10^{5}$ & $3.41 \times 10^{6}$ & $3,19 \times 10^{6}$ \\
\hline $364-5$ & & $9.45 \times 10^{5}$ & $3.08 \times 10^{6}$ & $2.09 \times 10^{6}$ \\
\hline Mean & & $1.17 \times 10^{6}$ & $2.76 \times 10^{6}$ & $2.31 \times 10^{6}$ \\
\hline $365-1$ & Bet E2 & $4.43 \times 10^{6}$ & $6.08 \times 10^{6}$ & $1.96 \times 10^{6}$ \\
\hline $365-2$ & & $8.85 \times 10^{5}$ & $9.77 \times 10^{6}$ & $1.78 \times 10^{6}$ \\
\hline $365-3$ & & $7.14 \times 10^{6}$ & $1.77 \times 10^{7}$ & $1.06 \times 10^{7}$ \\
\hline $365-4$ & & $2.88 \times 10^{6}$ & $5.65 \times 10^{6}$ & $6.10 \times 10^{6}$ \\
\hline Mean & & $3.83 \times 10^{6}$ & $9.81 \times 10^{6}$ & $5.10 \times 10^{6}$ \\
\hline $366-1$ & Bet E1 & $1.32 \times 10^{6}$ & $3.20 \times 10^{6}$ & $2.30 \times 10^{6}$ \\
\hline $366-2$ & & $1.17 \times 10^{6}$ & $4.96 \times 10^{6}$ & $3.83 \times 10^{6}$ \\
\hline $366-3$ & & $8.89 \times 10^{3}$ & $2.64 \times 10^{4}$ & $2.51 \times 10^{4}$ \\
\hline $366-4$ & & $5.35 \times 10^{5}$ & $1.35 \times 10^{6}$ & $7.28 \times 10^{4}$ \\
\hline Mean & & $7.61 \times 10^{5}$ & $2.38 \times 10^{6}$ & $1.56 \times 10^{6}$ \\
\hline $366-1$ & Bet E2 & $8.73 \times 10^{6}$ & $2.90 \times 10^{7}$ & $3.25 \times 10^{7}$ \\
\hline $366-2$ & & $1.10 \times 10^{7}$ & $3.81 \times 10^{7}$ & $1.86 \times 10^{7}$ \\
\hline $366-3$ & & $1.13 \times 10^{4}$ & $3.78 \times 10^{4}$ & $3.80 \times 10^{4}$ \\
\hline $366-4$ & & $1.18 \times 10^{7}$ & $3.62 \times 10^{7}$ & $2.01 \times 10^{7}$ \\
\hline Mean & & $7.89 \times 10^{6}$ & $2.58 \times 10^{7}$ & $1.78 \times 10^{7}$ \\
\hline $375-1$ & Bet E1-E2 & $4.30 \times 10^{6}$ & $3.49 \times 10^{7}$ & $1.84 \times 10^{7}$ \\
\hline $375-2$ & & $2.32 \times 10^{4}$ & $1.06 \times 10^{6}$ & n.a. \\
\hline $375-3$ & & $1.32 \times 10^{6}$ & $1.01 \times 10^{7}$ & $4.07 \times 10^{6}$ \\
\hline $375-4$ & & $5.98 \times 10^{4}$ & $8.34 \times 10^{5}$ & $6.84 \times 10^{5}$ \\
\hline Mean & & $1.43 \times 10^{6}$ & $1.17 \times 10^{7}$ & $7.72 \times 10^{6}$ \\
\hline
\end{tabular}

n. a. - serum not available

correspondence to: DennerJ@rki.de,

Robert Koch Institute, Center for HIV and Retrovirology, Berlin, Nordufer 20, 13553 Germany 


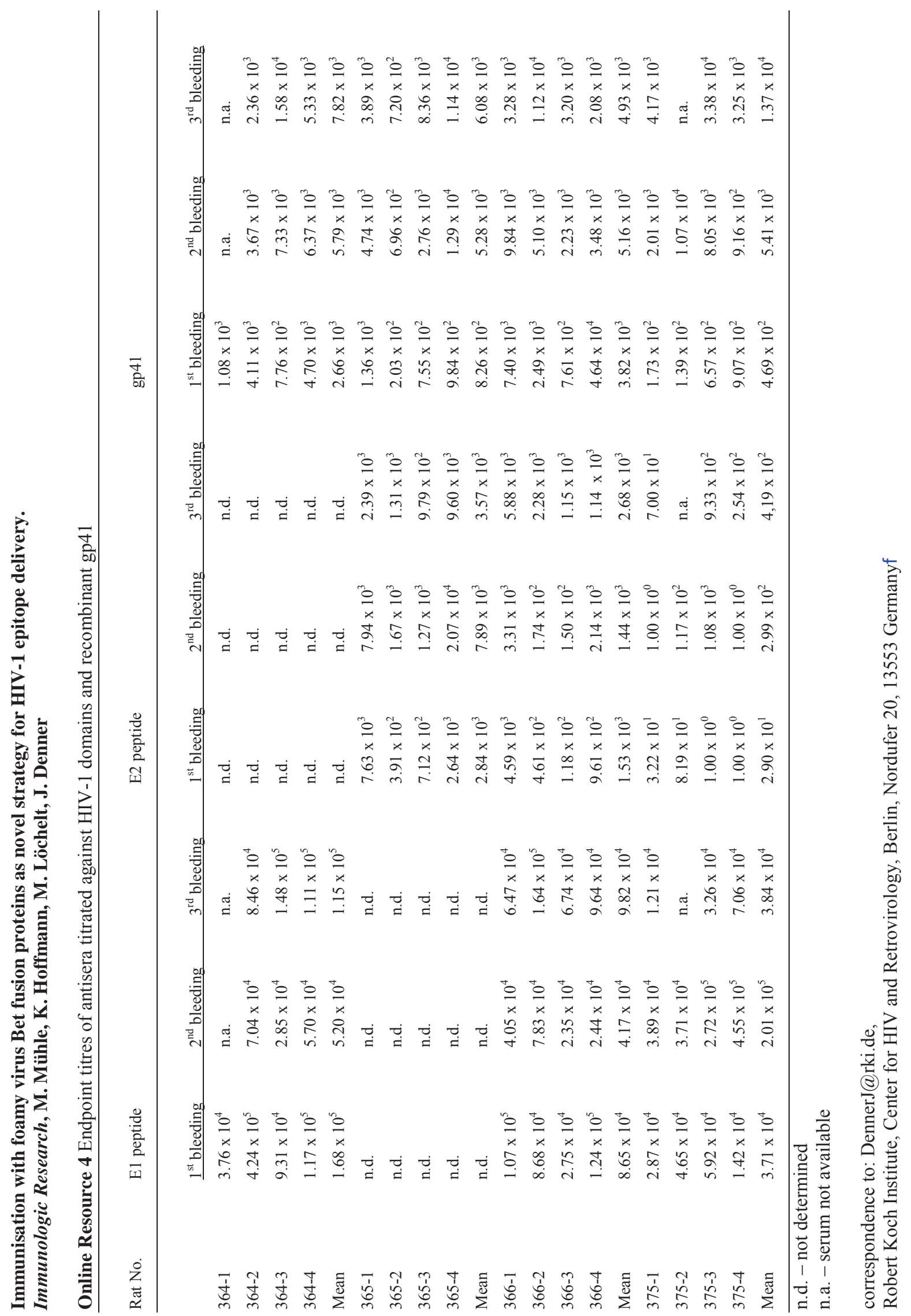




\section{Immunisation with foamy virus Bet fusion proteins as novel strategy for HIV-1 epitope delivery. Immunologic Research, M. Mühle, K. Hoffmann, M. Löchelt, J. Denner}

\section{Online Resource 5}

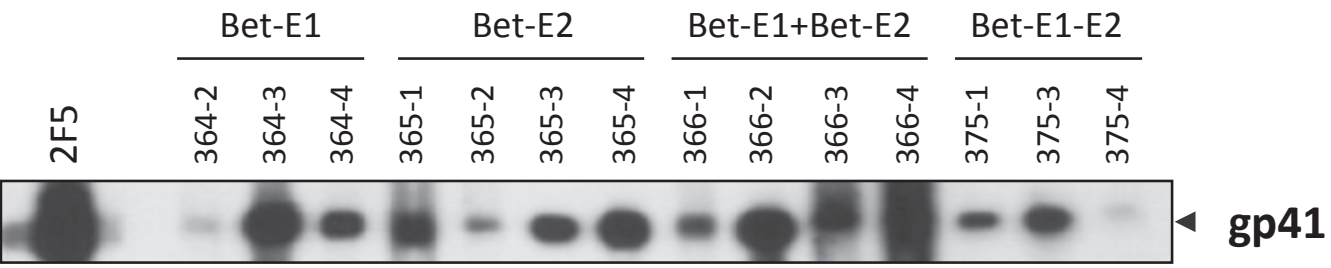

Western blot analysis of antisera of the final bleeding using purified recombinant gp41 as antigen (200 ng gp41/lane). Antisera (1:1000) were incubated on the membrane using a slot blot chamber and an anti-rat HRP-labelled secondary antibody for detection. The number of the animals is indicated. 2F5 was used as positive control $(113 \mathrm{ng} / \mathrm{ml})$ 


\title{
Immunisation with foamy virus Bet fusion proteins as novel \\ strategy for HIV-1 epitope delivery. Immunologic Research,
}

\author{
M. Mühle, K. Hoffmann, M. Löchelt, J. Denner
}

\section{Online Resource 6}
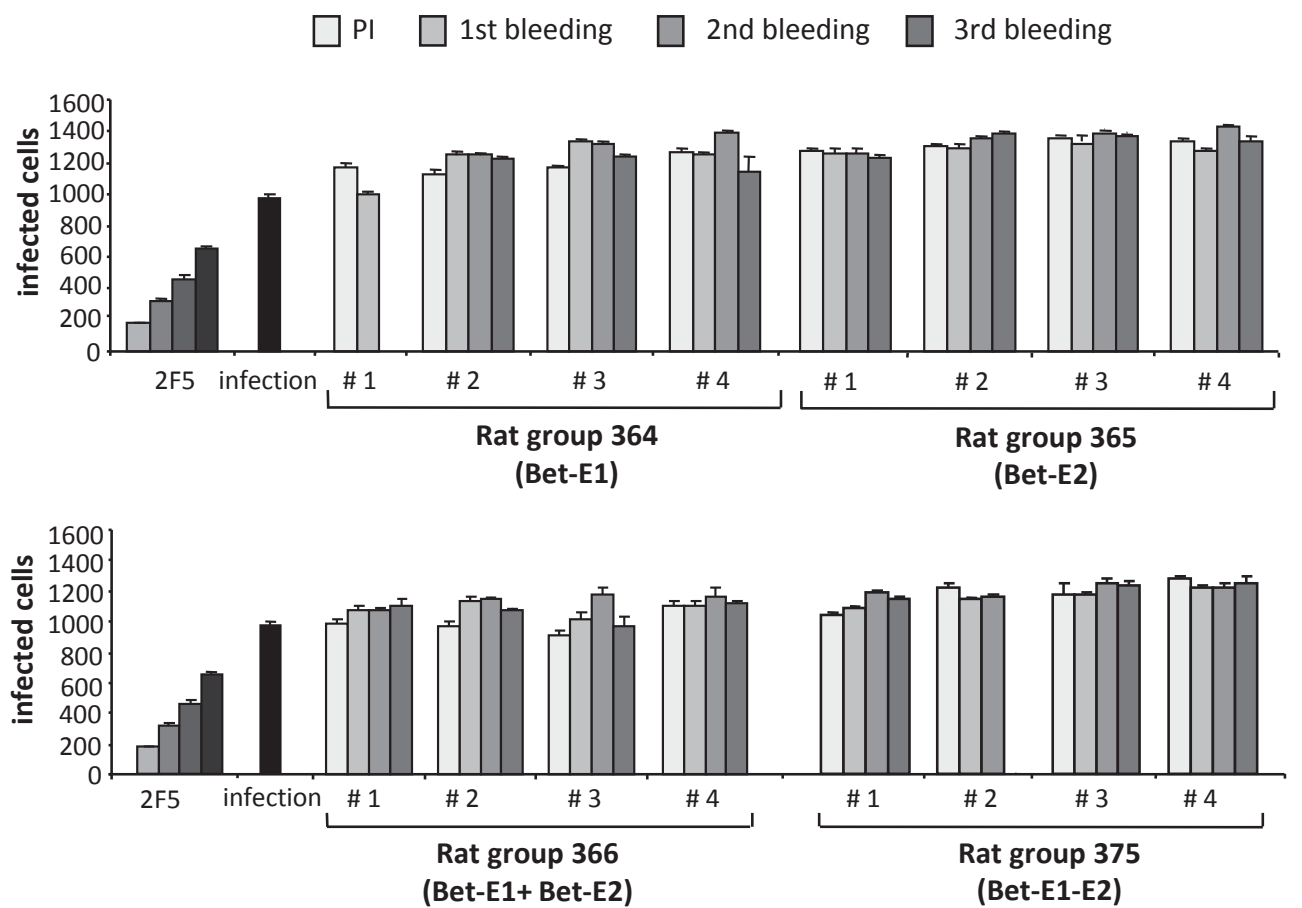

Neutralisation assays based on TZM-bl cells and titrated HIV-pNL-4.3. Virus was incubated for $30 \mathrm{~min}$ at $37^{\circ} \mathrm{C}$ with either $2 \mathrm{~F} 5(25,12.5,6.25$ and $3.12 \mu \mathrm{g} / \mathrm{ml}$, positive control), pre-immune sera (PI) or immune sera (1:50) of the indicated animal group (364-375), animal number (\#1-4) and bleeding and then added to TZM-bl cells plated one day in advance. $48 \mathrm{~h}$ after assay setup, cells were stained for infection with X-gal and colonies counted using an ELISPOT-reader. Neutralisation was defined as $50 \%$ reduction of stained cells when immune sera and preimmune sera were compared. Whereas $2 \mathrm{~F} 5$ was effectively neutralising, none of the immune sera achieved reduction of viral infection by more than $50 \%$ 